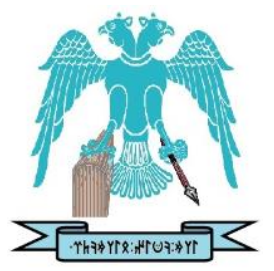

JOURNAL OF ENERGY SYSTEMS

2022, 6(1)

\title{
Analysis and design of an air to air heat exchanger used in energy recovery systems
}

\author{
Helin Ülgen Elmacıoğlu (D) \\ Yaşar University, Energy Systems Engineering Department, Izmir, Türkiye, helinulgen@ gmail.com \\ İrem Özsevgin (D) \\ Yaşar University, Energy Systems Engineering Department, Izmir, Türkiye, iremozsevgin@gmail.com \\ Cennet Kocabiyık \\ Yaşar University, Energy Systems Engineering Department, Izmir, Türkiye, cennetkocabiyik1@ gmail.com \\ Nezir Yağız Çam (iD \\ Yaşar University, Energy Systems Engineering Department, Izmir, Türkiye, nezir.cam@ yasar.edu.tr \\ *Levent Bilir (iD) \\ Yaşar University, Energy Systems Engineering Department, Izmir, Türkiye, levent.bilir@ yasar.edu.tr
}

\begin{tabular}{|c|c|c|c|}
\hline & $\begin{array}{l}\text { Submitted: } \\
\text { Accepted: } \\
\text { Published: }\end{array}$ & $\begin{array}{l}05.07 .2021 \\
19.11 .2021 \\
31.03 .2022\end{array}$ & $\begin{array}{l}\text { (W) } \\
\text { Check for } \\
\text { updates }\end{array}$ \\
\hline * Corresponding Author & & & \\
\hline
\end{tabular}

* Corresponding Author

Abstract: With the continuous worldwide energy use increase, energy efficiency is gaining high importance. Consequently, many methods have been investigated for potential energy savings. One of these methods is the use of heat recovery systems. These systems basically re-use waste heat and reduce energy consumption. Also, they are increasingly used to reduce heating and cooling demands of buildings. Their main feature is to provide fresh air to the place which is heated by the exhaust air with the help of a heat exchanger (HEX) working between two different temperature sources. The most commonly used types of heat exchangers in ventilation systems are cross-flow and counter-flow heat exchangers. Cross-flow heat exchangers have a thermal efficiency in the range of 50-75\% while counter-flow heat exchangers have 75-95\%. Many studies have been carried out to increase the efficiency of this type of heat exchangers. In this study, different designs of crossflow and counter-flow exchangers are compared using ANSYS Fluent software. The aim is to determine how the plate surface geometry affects heat transfer and pressure drop. It is aimed to find the optimum design with maximum efficiency, high heat transfer and low pressure drop for heat exchangers. As a result, it has been observed that thermal efficiency increased from $18 \%$ to $60 \%$ when changing from cross flow to counter flow in flat plate design, while it increased from $25 \%$ to $77 \%$ in enhanced plate designs. For enhanced designs, counter flow heat exchanger is $52 \%$ more efficient than cross flow heat exchanger. Also, improvements to increase the surface area and turbulence in both flow types have increased heat transfer and thermal efficiency.

Keywords: $\quad$ ANSYS-Fluent analysis, Counter-flow, Cross-flow, Heat exchanger design, Heat recovery

Elmacığlu, H.Ü., Özsevgin, İ., Kocabiyık, C., Çam, N.Y., \& Bilir, L., Analysis and design of an air to air heat
Cite this paper as: $\quad \begin{aligned} & \text { exchanger used in energy recovery systems. Journal of Energy Systems 2022; 6(1): 108-130, DOI: } \\ & 10.30521 / \text { jes.962672 }\end{aligned}$

(c) 2022 Published by peer-reviewed open access scientific journal, JES at DergiPark (https://dergipark.org.tr/en/pub/jes)

\begin{tabular}{|c|c|c|c|}
\hline \multicolumn{2}{|c|}{ Nomenclature } & \multirow[b]{2}{*}{$P_{\text {fan }}$} & \multirow[b]{2}{*}{ Fan power $[\mathrm{W}]$} \\
\hline A & $\begin{array}{l}\text { Last period with a negative discounted cumulative } \\
\text { cash flow [-] }\end{array}$ & & \\
\hline $\mathrm{B}$ & $\begin{array}{l}\text { Absolute value of discounted cumulative cash flow at } \\
\text { the end of the period A [-] }\end{array}$ & $\Delta \mathrm{P}$ & Pressure drop $[\mathrm{Pa}]$ \\
\hline $\mathrm{C}$ & Discounted cash flow during the period after A [-] & $\mathrm{R}_{\mathrm{t}}$ & Net cash inflow-outflows during a single period t \\
\hline $\mathrm{i}$ & $\begin{array}{l}\text { Discount rate or return that could be earned in } \\
\text { alternative investments [-] }\end{array}$ & Q & Heat transfer $[\mathrm{W}]$ \\
\hline $\mathrm{n}$ & Plate number [-] & $Q_{\text {total }}$ & Total heat transfer [W] \\
\hline $\mathrm{t}$ & Time $[\mathrm{s}]$ & $\dot{Q}$ & Heat transfer rate $[\mathrm{kW}]$ \\
\hline $\mathrm{t}$ & Number of times periods [-] & $\dot{\mathrm{V}}$ & Volumetric flow rate $\left[\mathrm{m}^{3} / \mathrm{s}\right]$ \\
\hline $\mathrm{t}_{11}$ & Warm air inlet temperature $\left[{ }^{\circ} \mathrm{C}\right]$ & $\mathrm{X}_{\mathrm{CO}_{2}}$ & $\mathrm{CO}_{2}$ emission reduced in a period of time $\left[\mathrm{kg} \mathrm{CO}_{2}\right]$ \\
\hline$t_{12}$ & Warm air outlet temperature $\left[{ }^{\circ} \mathrm{C}\right]$ & $\mathrm{Y}_{\mathrm{CO}_{2}}$ & Emission value for the energy option (fuel) [-] \\
\hline$t_{21}$ & Cold air inlet temperature $\left[{ }^{\circ} \mathrm{C}\right]$ & $\dot{\mathrm{W}}_{\text {energy }}$ & Energy rate of the energy option [-] \\
\hline$t_{22}$ & Cold air outlet temperature $\left[{ }^{\circ} \mathrm{C}\right]$ & $\dot{\mathrm{m}}$ & Mass flow rate $[\mathrm{kg} / \mathrm{s}]$ \\
\hline $\mathrm{u}$ & X-velocity $[\mathrm{m} / \mathrm{s}]$ & $\mathrm{t}_{\text {working }}$ & Working hours of the related system [-] \\
\hline $\mathrm{v}$ & Y-velocity $[\mathrm{m} / \mathrm{s}]$ & $\rho$ & Density $\left[\mathrm{kg} / \mathrm{m}^{3}\right]$ \\
\hline $\mathrm{w}$ & Z-velocity $[\mathrm{m} / \mathrm{s}]$ & $\eta$ & Thermal efficiency [-] \\
\hline
\end{tabular}




\section{INTRODUCTION}

A significant part of the total energy used by a country is used in buildings in the residential and commercial sectors. In the project design and development process of a building, it is necessary to adopt environmentally friendly applications and solutions that lead to a reduction of energy consumption for heating, cooling and ventilation. Since an important part of the total energy consumption is generated by air handling units, an efficient and energy-saving system is needed to minimize energy consumption in buildings. As a result of certain studies, heat recovery systems have started to be used in order to reduce energy consumption while increasing energy efficiency [1]. Heat recovery systems are energy recovery ventilation systems that provide fresh, highly filtered air that improves the indoor environment while recovering the normally wasted heat. Heat recovery ventilation works independently of the normal heating system. Each room has ventilation ducts, all of which lead to a heat exchanger, filtering air entering and leaving the zone. Heat Exchanger (HEX) is the main device used in the recovery of wasted heat and may have certain applications in space heating, air conditioning and waste heat recovery.

There are various heat exchangers tailored to different engineering applications with many different sizes, weights, shapes and flow patterns [2]. The performance of heat exchangers can be studied using different flow types for different systems to improve cooling performance of cabinet cooling system with cross flow heat exchanger and results of the model are compared with counter flow plate heat exchanger. As an outcome of this study, it can be said that the systems with cross-flow plate heat exchanger has greater cooling performance and lower thermal resistance while comparing with the system with counter-flow heat exchanger for large width of cabinet cooling system [3]. In another study, experimental analysis was performed with heat exchangers with different geometries for evaporative coolers. It has been observed that different plate protrusions increase the heat transfer efficiency and lead to a lower pressure drop [4].

Studies for improvement in heat exchangers have generally been carried out on surface geometry. This is because it is not possible to change the fluid or flow used in certain systems. In order to see the effect of the protrusions on the heat transfer, in cross flow, flat and dimpled plates were compared, and it has been observed that the heat transfer performance on the dimpled plate is always better for the crossflow [5]. In the pillow-shape plate study, similar to the dimple design, it was observed that the dimpled pillow plate provided a two percent increase in the heat transfer rate [6]. Dimple design has also been tried in tube heat exchangers. In a study, dimple inserts were made on the surface of the tube heat exchanger, and it was observed that these dimples increased the heat transfer [7]. In another experimental analysis of tube heat exchanger, comparisons were made using a computational fluid dynamics (CFD) program. Heat transfer rate, heat transfer coefficient and efficiencies were compared for plain and spherical dimpled tube. It turns out that the use of water in a spherical dimpled tube increases the heat transfer rate, overall heat transfer coefficient as well as efficiency compared to a plain tube [8]. Experimental study was carried out for 2 different plates of air-to-air heat exchangers used for heat recovery ventilation. The results showed that the cooling capacity of the dimple surface heat exchanger as a ventilation heat recovery system in cooling mode is $50-60 \%$ better than that of the flat surface plate heat exchanger [9]. Two different analyzes were performed with circular and elliptical finned tube heat exchangers. It was found that the heat transfer rate was better in elliptic tubes and the pressure drop was lower [10]. In addition to the greater efficiency of the elliptical tubes, the tube heat exchangers were also tested with corrugated fin profile with different fluted domains. Corrugated fins have been observed to improve the pressure distribution on the pipe surfaces regularly [11]. In one of the studies, friction factor and Nusselt number in a heat exchanger with hollow and protruding plates were investigated according to the geometric and working conditions. As a result, Nusselt number and friction factor correlations were obtained which can be applied to various geometric parameters and operating conditions [12]. In another study, flow properties and heat transfer performance in heat exchanger channels were analyzed numerically and experimentally for different dimple geometries. The dimples 
have been found to cause downflow, improve flow mixing and reconnection, cut the boundary layer and generate periodic impinging flows, which then greatly improve heat transfer [13].

As can be seen from the studies, most of the heat transfer improvements are directed to altering the flow regime and increasing the heat transfer area by making changes in the surface geometry of the heat exchangers. Surface geometries have very different combinations in terms of placement and alteration of the geometric properties of different shapes, and therefore many researches have been made in these fields. In this study, design changes were made in two different flow types; cross-flow and counter-flow, and the effect of these changes on heat transfer and pressure drop was investigated. In addition, thermal, economic and environmental analyzes of these designs in heat exchangers were also carried out.

\section{SYSTEM DESCRIPTION}

A plate heat exchanger works in a rather straight forward process. Two neighboring plates create channels for the air to pass through. The supply air passes on one side of the plate and the exhaust air on the other side. Within the scope of this study, heat exchangers with two different flow types; crossflow and counter-flow, were investigated. The view of cross-flow and cross-counter-flow heat exchangers are illustrated in Figs. 1, 2, respectively. These views include only one cold air passage and half hot air passages on the top and bottom of cold air passage with plates between them.

The cross-flow heat exchanger has a design in which two air streams will enter the heat exchanger perpendicular to each other. The thermal energy is exchanged via the panels. This type of airflow regulation increases efficiency but does not increase above of 75\% [14].

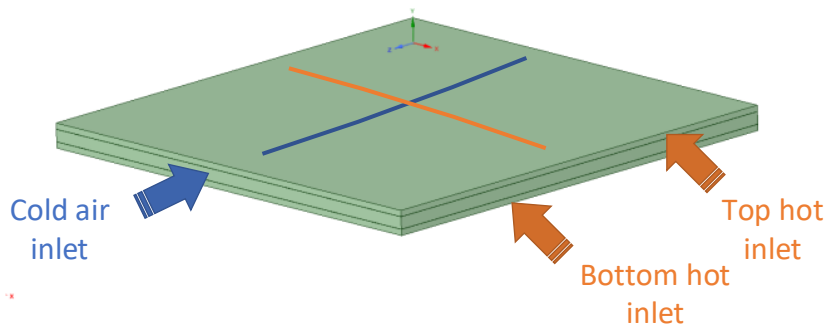

Figure 1. Cross-flow model.

The thermal efficiency of cross-flow heat exchanger is between the efficiency of counter flow and parallel flow heat exchangers. However, the cross-flow heat exchanger is commonly used because of its relatively small and inexpensive production unit that has sufficient efficiency.

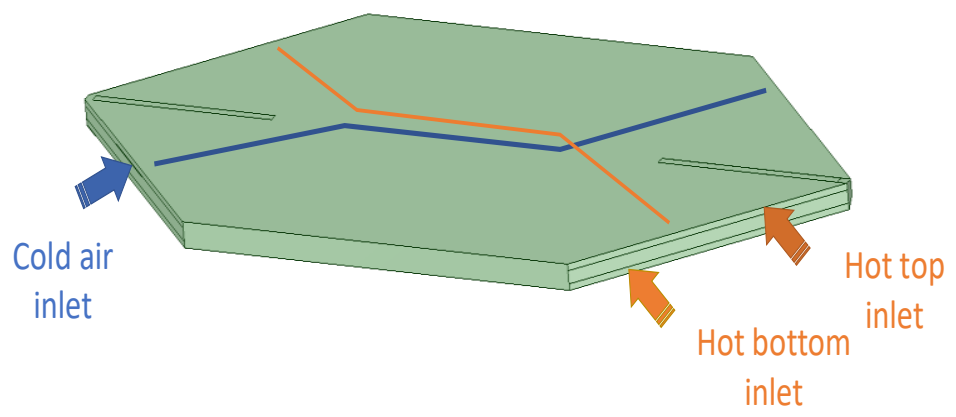

Figure 2. Cross-Counter-flow model.

The efficiency of overall heat transfer depends on the heat transfer area. The cross-counter flow type solves this problem with having a middle counter-flow area that increases the heat transfer area thus, 
increases efficiency. This is generally a convenient way to increase efficiency, but it is less thermally efficient than a completely reverse flow design. Completely reverse flow design is called counter-flow and theoretically it can provide an efficiency up to $100 \%$.

Efficiency increasing methods are not limited to flow change and heat transfer area. There are additional design features that are used for this purpose, such as rib turbulators, pins arrays, and more recently transition surfaces including dimples. This is because improvements in magnification levels are useful in a variety of practical applications such as macro and micro scale heat exchangers, electronic cooling [15]. Some of the examples of such additions are seen in Fig. 3(a) as protrusions and waves and Fig. $3(b)$ as dimples.

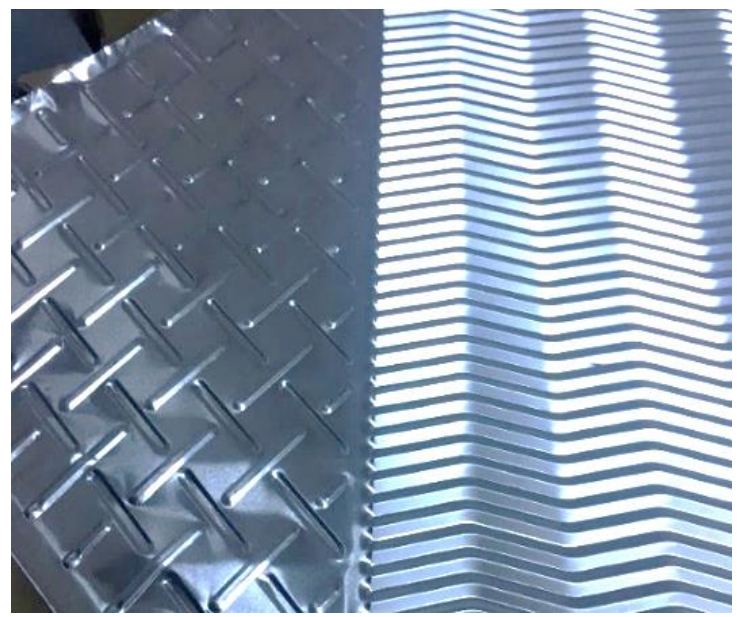

(a)

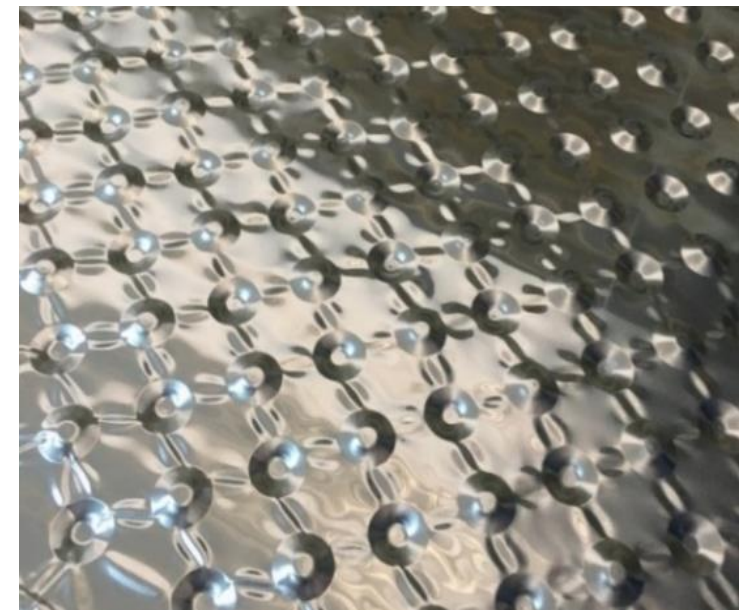

(b)

Figure 3. a) Protrusions and waves, b) Dimples

One of the important parameters for the performance of a plate heat exchanger is the spacing between the plates. A narrow channel leads to high-pressure drop but also to high efficiency. If a lower pressure drop is required, it is better to use a higher channel spacing. The trade-off is lower efficiency.

\subsection{Cross-Flow Model}

For the cross-flow heat exchanger, a 500x500 $\mathrm{mm}$ plate and a $6.5 \mathrm{~mm}$ channel height model was created. In order to make an accurate comparison, design changes were made as an attachment on the plate without changing the plate size and channel height. The geometry of the cross-flow model consisted of 3 different layers; hot side air, plate and cold side air. Hot and cold air volumes are drawn as symmetry in order to reduce the element size in the mesh. The geometrical properties of the cross-flow model is shown in Fig. 4(a,b).

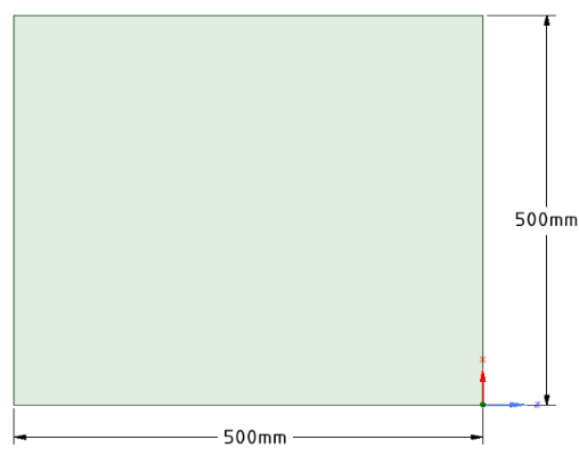

(a)

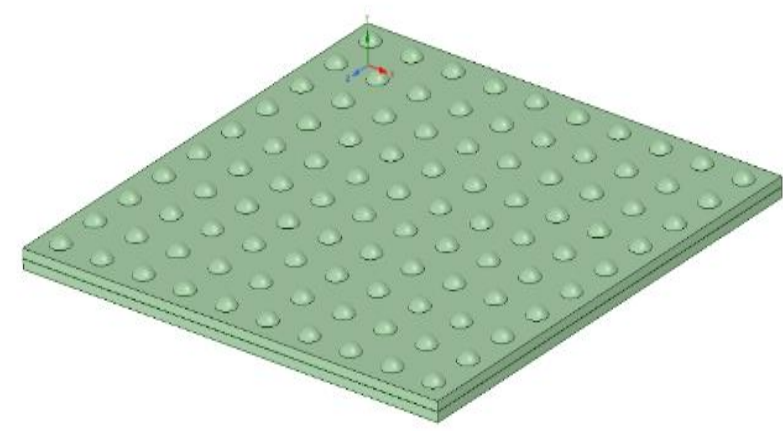

(b)

Figure 4. (a) Size and (b) geometry of the cross-flow model. 
The reason for not taking two half hot flows as in flat plate analysis was that the dimple inserts increase the heat transfer area, which makes analysis process harder in personal computers. Dimples were added to the flat plate in design analysis. Later, dimple diameter and velocity analysis were conducted. The purpose of these analyzes was to observe the effect of dimple dimensions and air intake velocity on heat transfer and pressure drop. Three different designs with diameter of $22 \mathrm{~mm}, 26 \mathrm{~mm}$ and $30 \mathrm{~mm}$ were made for the analysis. Dimple diameters are shown in Fig. 5.

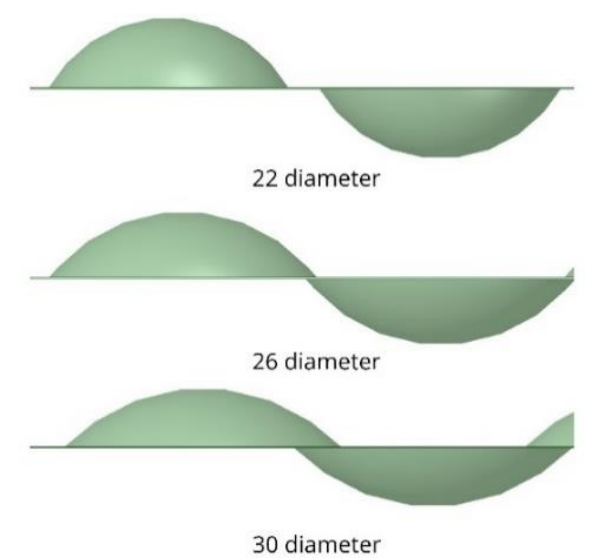

Figure 5. Dimple diameters.

Table 1. Cross-flow analysis parameters.

\begin{tabular}{llcc}
\hline Flow & Parameter Name & Parameter Unit & Parameters \\
\hline \multirow{6}{*}{ Plate Size } & $\mathrm{mm}$ & $500 \times 500$ \\
& Thickness of Plate & $\mathrm{mm}$ & 0.165 \\
& Channel Height & $\mathrm{mm}$ & 13 \\
Cross & Dimple Height & $\mathrm{mm}$ & $22,26,30$ \\
& Number of Plates & - & 90 \\
& Exhaust Air Inlet Temperature & ${ }^{\circ} \mathrm{C}$ & 22 \\
& Fresh Air Inlet Temperature & ${ }^{\circ} \mathrm{C}$ & 0 \\
& Exhaust and Fresh Air Inlet Velocity & $\mathrm{m} / \mathrm{s}$ & $3,5,8$ \\
\hline
\end{tabular}

Analyses were made for the velocity values of 3,5 and $8 \mathrm{~m} / \mathrm{s}$ for thermal performance evaluation. The purpose of these analyzes was to observe how the velocity factor affects heat transfer and pressure drop. For these analyzes dimple diameter models were used. These analyzes have looked at how design changes and velocity affect heat transfer, pressure drop and thermal efficiency. The parameters of the cross-flow model and analysis are given in the Table 1.

\subsection{Counter-Flow Model}

For the counter-flow heat exchanger a specific analysis area has been drawn by determining a flow path from the middle of the heat exchanger. It was because the geometry was too complex and it was difficult for personal computers to mesh such geometries. Plate size and plate thickness were kept constant in all analyzes. The channel height was also fixed in the analyzes other than channel height analysis. The full and selected analysis area are shown in Fig. 6. 


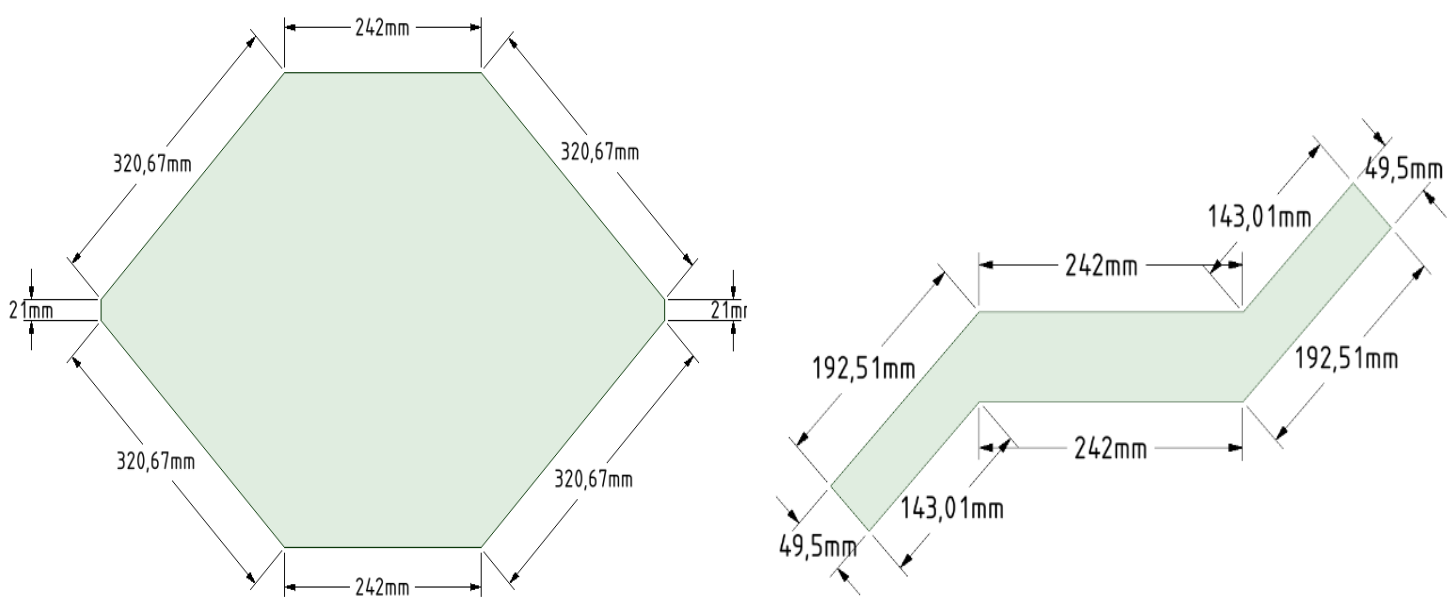

Figure 6. Full and selected area of counter-flow model.

The flow was decided to be counter due to the changing analysis area. The new model consisted one hot air in the upper channel and one cold air in the lower channel. The counter-flow model with the selected analysis model is shown in Fig. 7.

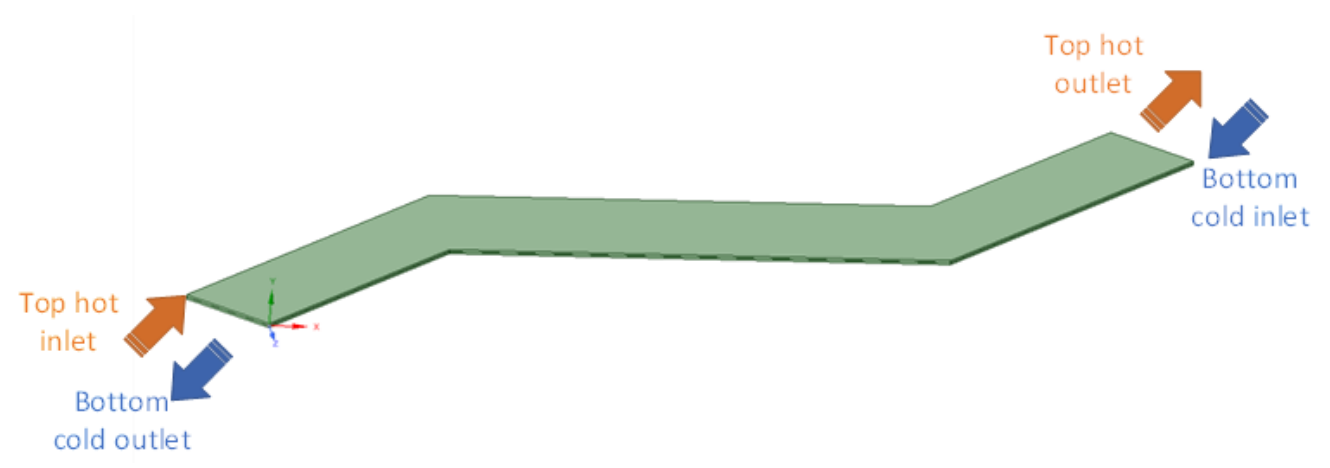

Figure 7. Analysis model of counter-flow.

As in cross-flow, in order to look at the effect of design changes, flat plate analysis was performed first. Afterwards, the inlet and outlet channels were left flat and waves was inserted in the middle. For wavy plate analysis, half hot and cold flow separated by the plate modeling was done as in flat plate analysis. The inlet and outlet channels are left flat and a half cylinders with a radius of $1 \mathrm{~mm}$ were added to the middle of the plate and the waveform is given in Fig. 8.

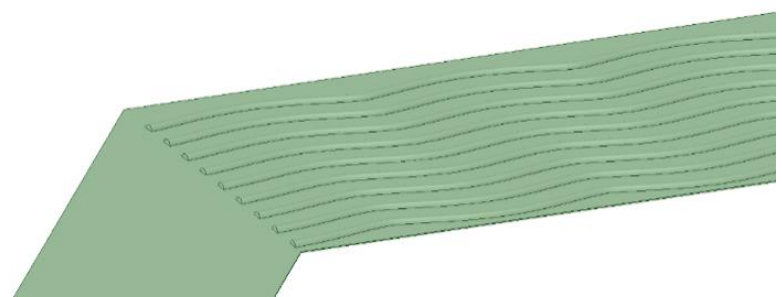

Figure 8. Wavy plate model.

Later, effects of angle of cylindrical protrusions were examined. These analyzes were performed on wavy plates with cylindrical protrusions on the inlet and outlet channels. 6 designs were made, in which cylindrical protrusions were placed with different angles (Fig. 9). The purpose of these analyzes was to observe how the protrusions and angles affect the heat transfer and pressure drop. 


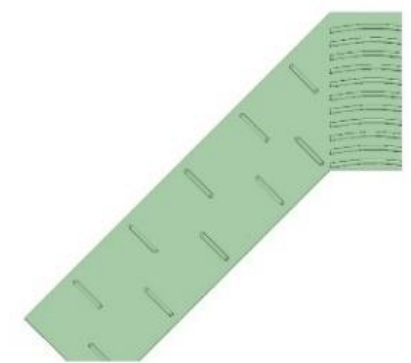

0 degree angle

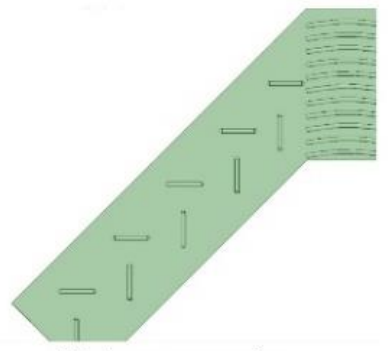

45 degree angle

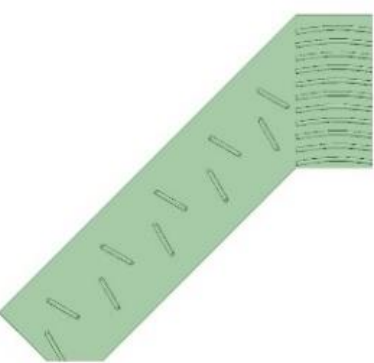

15 degree angle

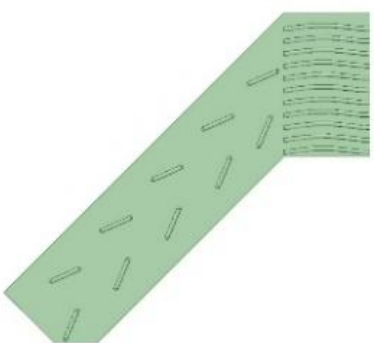

68 degree angle

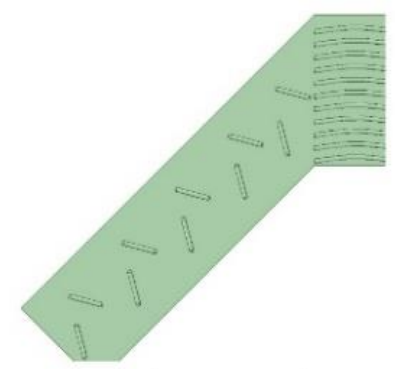

30 degree angle

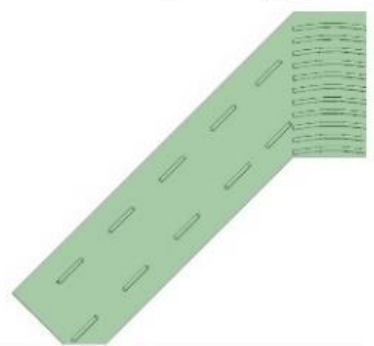

90 degree angle

Figure 9. Angles of cylindrical protrusions.

Table 2. Counter-flow analysis parameters.

\begin{tabular}{llcc}
\hline Flow & Parameter Name & Parameter Unit & Parameters \\
\hline \multirow{5}{*}{ Counter } & Thickness of Plate & $\mathrm{mm}$ & 0.2 \\
& Channel Height & $\mathrm{mm}$ & 3,4 \\
& Cylindrical Protrusion Angles & $\circ$ & $0,15,30,45,68,90$ \\
& Cylindrical Protrusion Height & $\mathrm{mm}$ & 1 \\
& Number of Plates & - & 145,195 \\
& Exhaust Air Inlet Temperature & ${ }^{\circ} \mathrm{C}$ & 22 \\
& Fresh Air Inlet Temperature & ${ }^{\circ} \mathrm{C}$ & 0 \\
& Exhaust and Fresh Air Inlet Velocity & $\mathrm{m} / \mathrm{s}$ & 5 \\
\hline
\end{tabular}

Three designs with $0^{\circ}, 45^{\circ}$ and $90^{\circ}$ angle protrusions were chosen from wavy and protruding designs. Six analyzes were made by designing models of these plates with $3 \mathrm{~mm}$ and $4 \mathrm{~mm}$ channel height. The purpose of these analyzes was to observe how duct height affects heat transfer and pressure drop. Some constant parameters such as velocity and temperature were used in the analyses. The parameters of the counter-flow model and analysis are given in the Table 2.

\section{DESIGN METHODOLOGY AND METHOD}

The aim of the study was to analyze the effect of the geometric shapes on the heat transfer and pressure drop on the surface of the plate and to determine the best design among them to increase the efficiency according to these results. For this reason, firstly, flat plate cross-flow heat exchanger analysis was performed to see how the geometric surface shapes affect the heat transfer. Then, the same method was repeated for counter-flow heat exchangers. Economic and environmental analysis results of these studies were also obtained.

\subsection{CFD}

The movement of the liquid in the physical domain depends on various properties. In order to elucidate the fluid flow behavior and develop a mathematical model, these features need to be defined in such a 
way as to allow the transition between the physical and numerical fields. Speed, pressure, temperature, density and viscosity are the main features that should be considered simultaneously when performing a fluid flow study. Combustion, multiphase flow, turbulence, mass transport, etc. Navier-Stokes equations are widely applied mathematical models to examine changes in these properties during dynamic and / or thermal interactions. The equations can be adjusted according to the content of the problem and expressed on the principles of mass, momentum and energy conservation [16].

The Navier-Stokes equations consist of a time-dependent continuity equation for the conservation of mass, the conservation of the triple momentum equations, and the conservation of the energy equation over time. Equations are a combined set of differential equations and can be solved in theory for a given flow problem using methods derived from mathematics. In the past, engineers have made further approximations and simplifications to the set of equations until they have a set of equations to solve. Recently, high speed computers have been used to solve approaches to equations using various techniques such as finite differences, finite volume, finite elements and spectral methods.

\subsubsection{Mesh generation in CFD}

In the CFD analysis, ANSYS Fluent software was preferred to understand the basic theory and calculation methods of the models for heat transfer applications. This software allows the monitoring of heat transfer, temperature and velocity values in a modeled 3D system.

Partial differential equations for governing fluid flow and heat transfer are generally unsuitable for analytical solutions, except very simple cases. Therefore, to analyze fluid flows, the flow areas are divided into smaller sub-areas. The management equations are then parsed and solved within each of these subfields. Care must be taken to ensure the smooth continuity of the solution between the common interfaces between the two subdomains, so that approximate solutions within the various sections can be combined to give a complete picture of the fluid flow across the entire domain. Subdomains are often called elements or cells, and the collection of all elements or cells is called mesh or grid (Fig. 10).

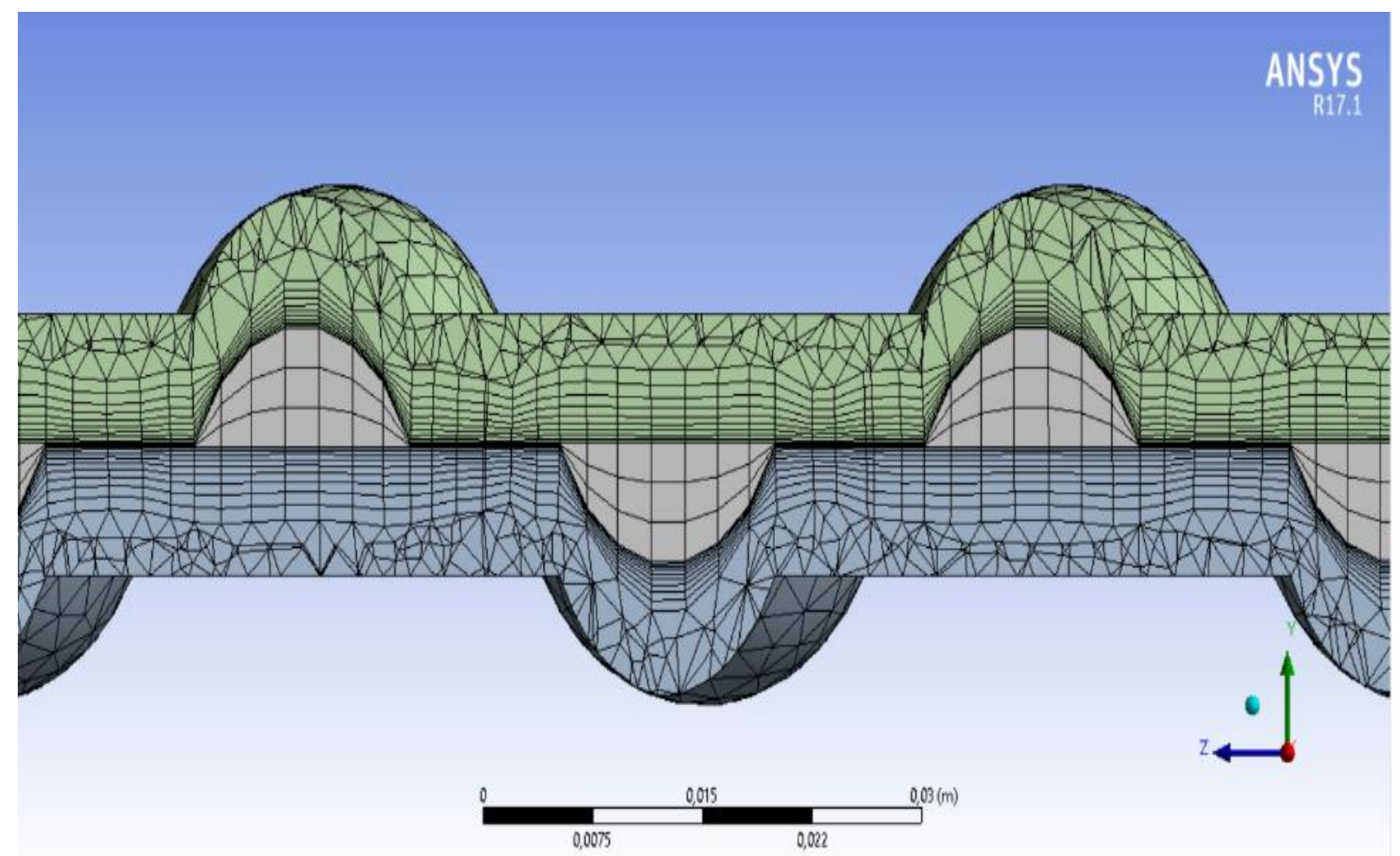

Figure 10. Meshed dimpled plate model. 
Obtaining a suitable mesh (or grid) is called mesh generation (or grid generation) and has long been considered a bottleneck in the analysis process due to the absence of a fully automated meshing procedure (Fig. 10). There are many features to make the mesh optimally and to divide it as desired. Also, because meshing typically uses a significant amount of time required to obtain simulation results, the better and more appropriate the meshing is, the faster and more accurate the solution is.

\subsubsection{Mesh independency and mesh quality}

When meshing, many different solutions can be achieved by increasing the number of mesh in the same geometry. Mesh or Grid independent solution is a solution that does not vary significantly even when the mesh is refined further. Mesh independence studies are conducted in CFD to make sure that the results are due to the boundary conditions and physics used, not the mesh resolution. When the mesh is increased or improved, changes can be observed in the results. However, there is a limit to which no change in results is observed even after making it finer. Mesh independence can vary from case to case, depending on the physics involved and flow structures seen. When the element size increase is not possible due to the computer features, mesh quality feature is used. Some mesh parameters are checked. If the values are in the range given for quality mesh, the solution can be made. These values are between 0.25-0.5 for skewness and between 0.80-1 for orthogonality. In this study, Fluent analyzes were made by considering these concepts. Since the mesh method changes depending on each geometry and system, different methods have been tried in order to get accurate results.

\subsection{Thermal Performance Analysis}

In thermal performance analysis, heat exchanger values were found by using the analysis values for one channel in all designs. Thermal performance calculation of the heat exchanger was made with heat transfer and fan power parameters. For comparison, velocity and inlet temperatures were taken as the same for all analyzes. Fan power is calculated with the mass flow rate and pressure drop values of the program. Firstly, volumetric flow rate was calculated using mass flow rate and air density by using the formula,

$$
\dot{V}=\frac{\dot{m}}{\rho}
$$

Then, fan power was found by using (Eq. 2).

$$
P_{\text {fan }}=\dot{V} \cdot \Delta P
$$

For heat transfer, the heat transfer values found for a single channel are multiplied by the number of plates. And it is expressed as,

$$
Q_{\text {total }}=Q n
$$

In thermal performance analysis, the number of plates was determined to cover the same height when the plates were placed on top of each other. Three different channel heights were used in the analysis. Table 3 show how many plates are used according to the channel height.

Table 3. Number of plates for channel height

\begin{tabular}{cc}
\hline Channel Height & Number of Plates \\
\hline $6.5 \mathrm{~mm}$ & 90 \\
$4 \mathrm{~mm}$ & 145 \\
$3 \mathrm{~mm}$ & 195 \\
\hline
\end{tabular}


Another important factor in the thermal performance analysis of heat exchangers is thermal efficiency. Thermal efficiencies of heat exchangers are calculated by using inlet and outlet temperatures. It can be expressed as [17];

where;

$$
\eta=\frac{t_{22}-t_{21}}{t_{11}-t_{21}}
$$

$t_{11}=$ Warm air inlet temperature,

$t_{12}=$ Warm air outlet temperature,

$t_{21}=$ Cold air inlet temperature,

$t_{22}=$ Cold air outlet temperature.

The purpose of these analyzes was to calculate the net gain by using the recovered heat and the fan power used in the system. In addition, by looking at the thermal efficiency values, it was aimed to observe which flow and design changes increase the efficiency.

\subsection{Economic Analysis Method}

In engineering, one of the important processes after the development and design of new products is economic analysis. Thanks to these analyzes, the product is informed about the profit-loss situation and return time.

In this project, 3 different methods are used: simple payback period, net present value and discounted payback period [18]. Simple payback period refers to the time it takes to recover the cost of an investment. In short, the payback period is the time an investment reaches breakeven. Shorter repayments mean better investments. Simple payback period of a project can be calculated with;

$$
\text { Payback period }=\frac{\text { Initial investment }}{\text { Net annual cash flow }}
$$

Net present value (NPV) is a method used to determine the current value of all future cash flows generated by a project, including the initial capital investment. For long-term projects with multiple cash flows, the net present value of a project is calculated by using the formula (Eq.6) below.

$$
\text { Net Present Value }=\sum_{t=0}^{n} \frac{R_{t}}{(1+i)^{t}}
$$

where;

$R_{t}=$ net cash inflow-outflows during a single period $t$

$I=$ discount rate or return that could be earned in alternative investments

$t=$ number of times periods

The discounted payback period is a capital budgeting procedure used to determine the profitability of a project. The difference from the simple payback method is that it takes into account the time value of money, which makes it more accurate. Discounted payback period formula can be expressed as;

where,

$$
\text { Discounted Payback Period }=A+\frac{B}{C} \text {, }
$$

$\mathrm{A}=$ Last period with a negative discounted cumulative cash flow;

$\mathrm{B}=$ Absolute value of discounted cumulative cash flow at the end of the period A

$\mathrm{C}=$ Discounted cash flow during the period after A. 


\subsection{Environmental Analysis Method}

It can be said that approximately one third of the energy consumption in the world and $36 \%$ of the carbon dioxide $\left(\mathrm{CO}_{2}\right)$ emissions are derived from the manufacturing industry. Some of these $\mathrm{CO}_{2}$ emissions are emitted at temperatures which can be used as a new heat source in the same application or in another application [13]. In many industrial processes, hot exhaust air is released into the environment without the use of its thermal energy. In our case ventilation systems are used to heat the incoming air which reduces the heating demand inside. By reducing the need for heating, the amount of fossil fuel burned also decreases. This ensures that the $\mathrm{CO}_{2}$ emitted outside is reduced.

The $\mathrm{CO}_{2}$ emission calculation in this system can be done by looking at parameters such as heat transfer, operating time of the system and the carbon dioxide emission value of the fuel burned. Annual reduced carbon dioxide emission values are calculated with the following formula:

where,

$$
X_{\mathrm{CO}_{2}}=Y_{\mathrm{CO}_{2}} \cdot \dot{W}_{\text {energy }} \cdot t_{\text {working }}
$$

$X_{\mathrm{CO}_{2}}: \mathrm{CO}_{2}$ emission reduced in a period of time $\left(\mathrm{kg} \mathrm{CO}_{2}\right)$

$Y_{\mathrm{CO}_{2}}$ : Emission value for the energy option (fuel)

$\dot{W}_{\text {energy }}$ : Energy rate of the energy option

$t_{\text {working }}$ : Working hours of the related system

The values are annual and have been found on the assumption that natural gas is used for heating. The natural gas $\mathrm{CO}_{2}$ emission values were used in calculations [19]. Annual $\mathrm{kWh}$ values are calculated by only taking into account the heating system operating in winter season.

\section{RESULTS AND DISCUSSION}

Analyzes are examined under four headings as design, thermal, economic and environmental. While thermal, economic and environmental analyzes are made over heat exchanger and ventilation systems, design changes are made on a single plate and are for a single channel.

\subsection{Based Designs}

In order to see the effect of the design changes, firstly flat plate analyzes were performed for both flows, cross-flow and counter-flow. With these analyzes, it was aimed to observe the effects of geometric shapes on the plate on temperature, heat transfer and pressure drop.

\subsubsection{Cross-flow flat plate}

For the cross-flow design, the plate size was 500 x $500 \mathrm{~mm}$ and the channel height was $6.5 \mathrm{~mm}$. With this design, one full cold air flow and two half hot air flows were modeled. Analyzes were made using the ANSYS Fluent software. With this program, it was aimed to obtain more accurate results and to observe the heat flow. Inlet, outlet and plate edges were divided into certain numbers to obtain different element sizes. Six analyzes were made with different element size values. As the number of meshes increased, the values first reached the Peak point, then progressively decreased and stabilized. This means that mesh independence was achieved. Table 4 shows the mesh quality value for different element sizes in terms of orthogonality and skewness.

Table 4. Mesh quality value

\begin{tabular}{llll}
\hline Mesh quality parameter & Coarse & Medium & Fine \\
\hline Orthogonal quality & 0.78 & 0.85 & 0.93 \\
Skewness & 0.46 & 0.34 & 0.25 \\
\hline
\end{tabular}




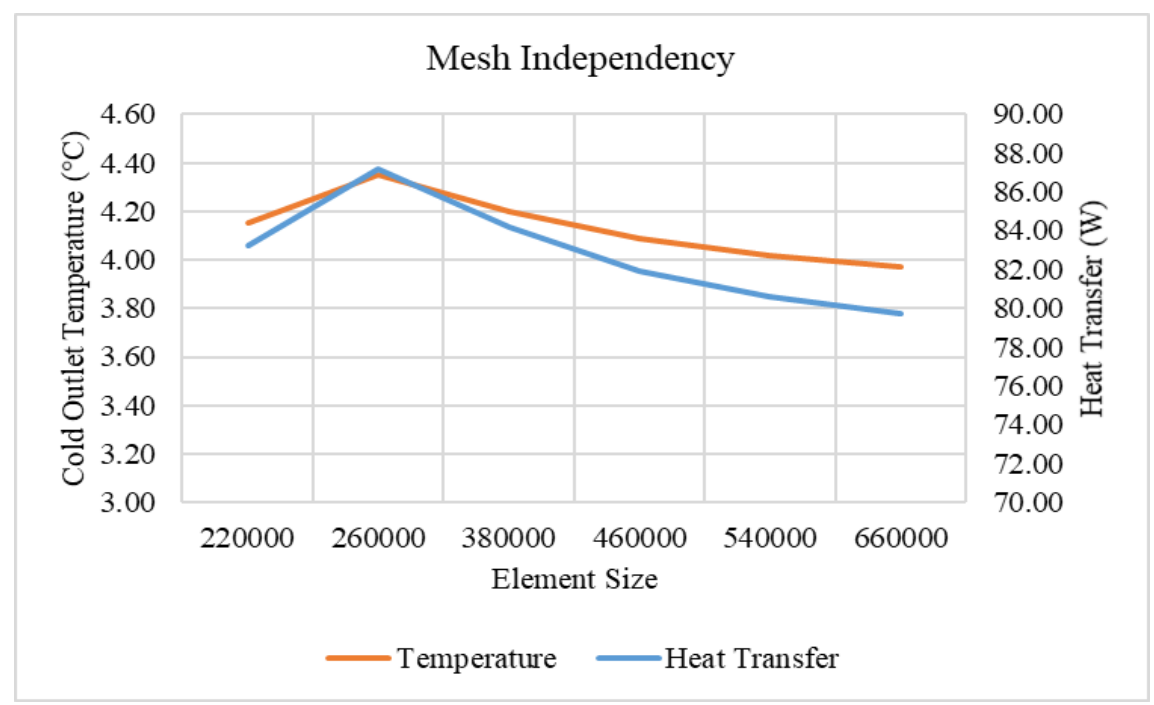

Figure 11. Mesh independency graph of cross-flow flat plate

Fig. 11 shows the output temperature and heat transfer in which the solution provides the independence of the mesh. It can be said that the analyzes with stabilized values of 460,000 (coarse), 560,000 (medium) and 660,000 (fine) element size have the most accurate results.

Table 5. Cross-flow flat plate results

\begin{tabular}{lc}
\hline & Cross-flow Flat Plate \\
\hline Cold Outlet Temperature $\left({ }^{\circ} \mathrm{C}\right)$ & 4.02 \\
Hot Outlet Temperature $\left({ }^{\circ} \mathrm{C}\right)$ & 17.97 \\
Heat Transfer $(\mathrm{W})$ & 80.62 \\
Pressure Drop $(\mathrm{Pa})$ & 13.88 \\
Efficiency $(\%)$ & $18 \%$ \\
\hline
\end{tabular}

As can be seen from the Table 5, cold air outlet temperature was calculated as about $4^{\circ} \mathrm{C}$ and hot air outlet temperature was calculated as about $18^{\circ} \mathrm{C}$. Heat transfer was approximately $80 \mathrm{~W}$ for single plate flow and the efficiency was $18 \%$.

\subsubsection{Counter-flow flat plate}

For the counter flow design, the flow path was determined from the middle of the full plate, creating an analysis area with a channel entrance of $49.5 \mathrm{~mm}$. Channel height was taken as $4 \mathrm{~mm}$. Using this design, one full cold and one full hot flow was modeled. Due to the size of the model, result accuracy was observed over mesh quality values instead of mesh independency. Mesh quality values were within suitable ranges.

Table 6. Counter-flow flat plate results.

\begin{tabular}{lc}
\hline & Counter-flow Flat Plate \\
\hline Element Size & $4,000,000$ \\
Cold Outlet Temperature $\left({ }^{\circ} \mathrm{C}\right)$ & 13.21 \\
Hot Outlet Temperature $\left({ }^{\circ} \mathrm{C}\right)$ & 8.78 \\
Heat Transfer $(\mathrm{W})$ & 108.82 \\
Pressure Drop (Pa) & 77.87 \\
Efficiency (\%) & $60 \%$ \\
\hline
\end{tabular}

Table 6 shows that cold air outlet temperature was $13.21^{\circ} \mathrm{C}$ and hot air outlet temperature was $8.78^{\circ} \mathrm{C}$. Heat transfer was approximately $109 \mathrm{~W}$ for single plate flow and the efficiency was $60 \%$. Compared to cross-flow, it can be said that the efficiency has increased from $18 \%$ to $60 \%$ with flow change in the same plate design. 


\subsection{Influence of Design Changes}

Different surface geometries have been tried in both flows during design changes. Dimpled, wavy and cylindrical protruding designs were used on the plate surface in the analyzes, and the sizes and angles of these inserts were changed. In addition, the effect of the channel height was observed. The effect of magnification levels with such changes has been examined.

\subsubsection{Influence of dimples on cross-flow}

This analysis was performed with dimpled plate for cross flow. For this purpose, firstly, it was decided that it would be more appropriate to use one half cold air stream and one-half hot air stream geometry. $22 \mathrm{~mm}$ diameter dimples were added to the $500 \times 500 \mathrm{~mm}$ sized plate. The channel height of this design was $6.5 \mathrm{~mm}$. Different designs have been tried to draw the geometry as similar to the real system as possible. Afterwards, a drawing was made which simplifies mesh making and gives the right solution and at the same time resembles the real design. As dimples increase the heat transfer area, the meshed area increases. Personal computers may have difficulty in doing so detailed analysis. For this reason, the necessary methods have been tried and the mesh shapes and their biases have been chosen in such a way that the most accurate results can be obtained. The plates were biased by using layers towards the plates in order to obtain a more detailed solution of the heat transfer plate and flow. After selecting the mesh method appropriately, 6 analyzes were performed with different element sizes. The values are almost stable in the last three analyzes. In order to facilitate comparison, the flat and dimpled plate values are given in the Table 7.

Table 7. Flat plate and dimpled plate comparison.

\begin{tabular}{lcc}
\hline & Flat-Plate & Dimpled-Plate \\
\hline Cold Outlet Temperature $\left({ }^{\circ} \mathrm{C}\right)$ & 4.02 & 5.20 \\
Hot Outlet Temperature $\left({ }^{\circ} \mathrm{C}\right)$ & 17.97 & 16.8 \\
Heat Transfer $(\mathrm{W})$ & 80.62 & 207.80 \\
Pressure Drop $(\mathrm{Pa})$ & 13.88 & 28.78 \\
\hline
\end{tabular}

As can be seen from the table, cold air outlet temperature was calculated as $5.20^{\circ} \mathrm{C}$ and hot air outlet temperature was calculated as $16.8^{\circ} \mathrm{C}$. Heat transfer was approximately $207.8 \mathrm{~W}$ for single plate flow. Single plate heat transfer value was approximately207.8 W. This value can be calculated for a 90-plate system as $18.702 \mathrm{~kW}$.

The comparison between flat plate and dimpled plate can be seen from the Table 7. The heat transfer of the dimpled-plate shows an increase of $157 \%$ compared to the flat-plate. With the increase of heat transfer, there was a $29.10 \%$ higher temperature increases than the flat plate in cold weather. With the increase in heat transfer and cold air temperature, the pressure drop approximately tripled. 


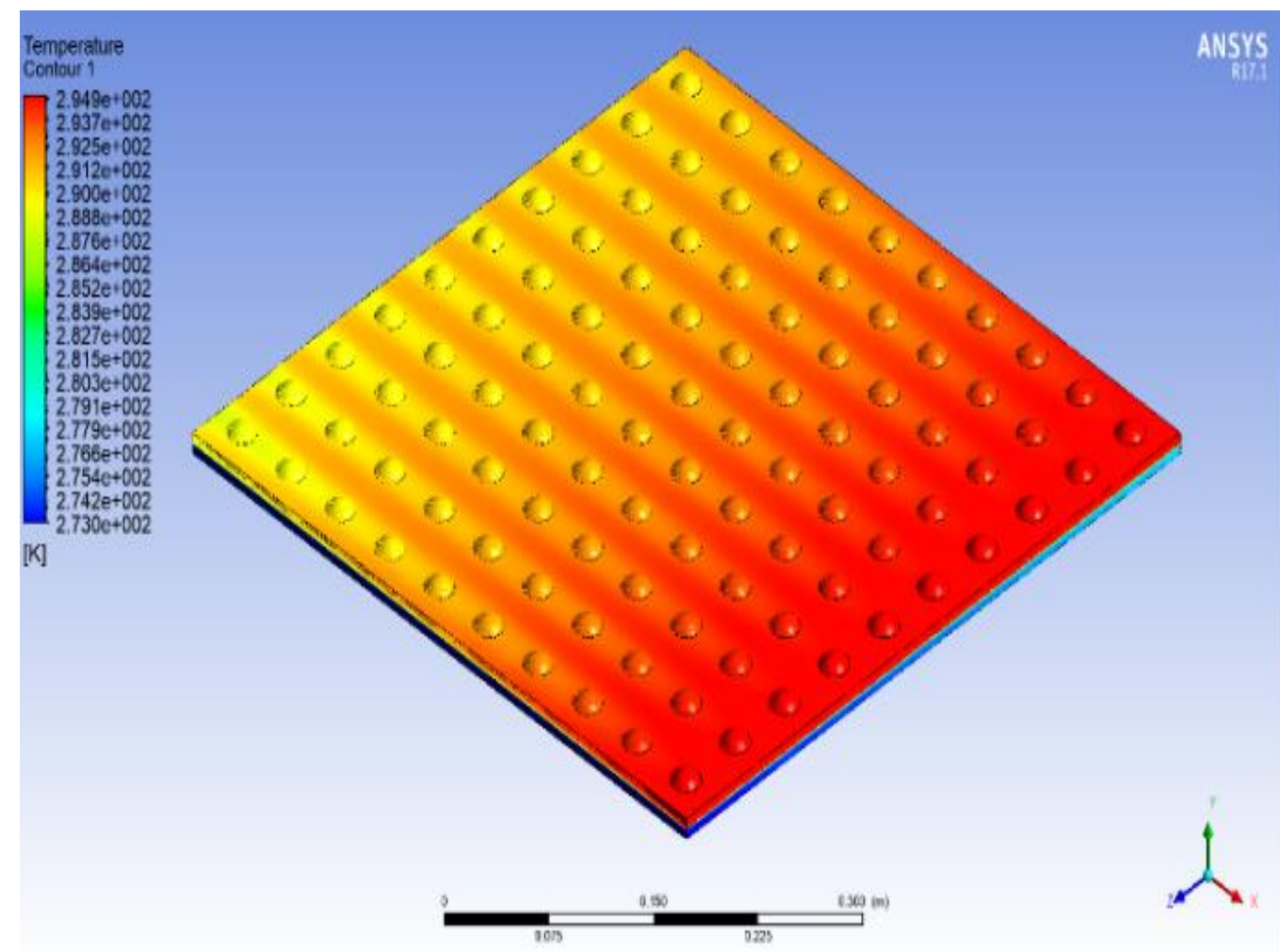

(a)

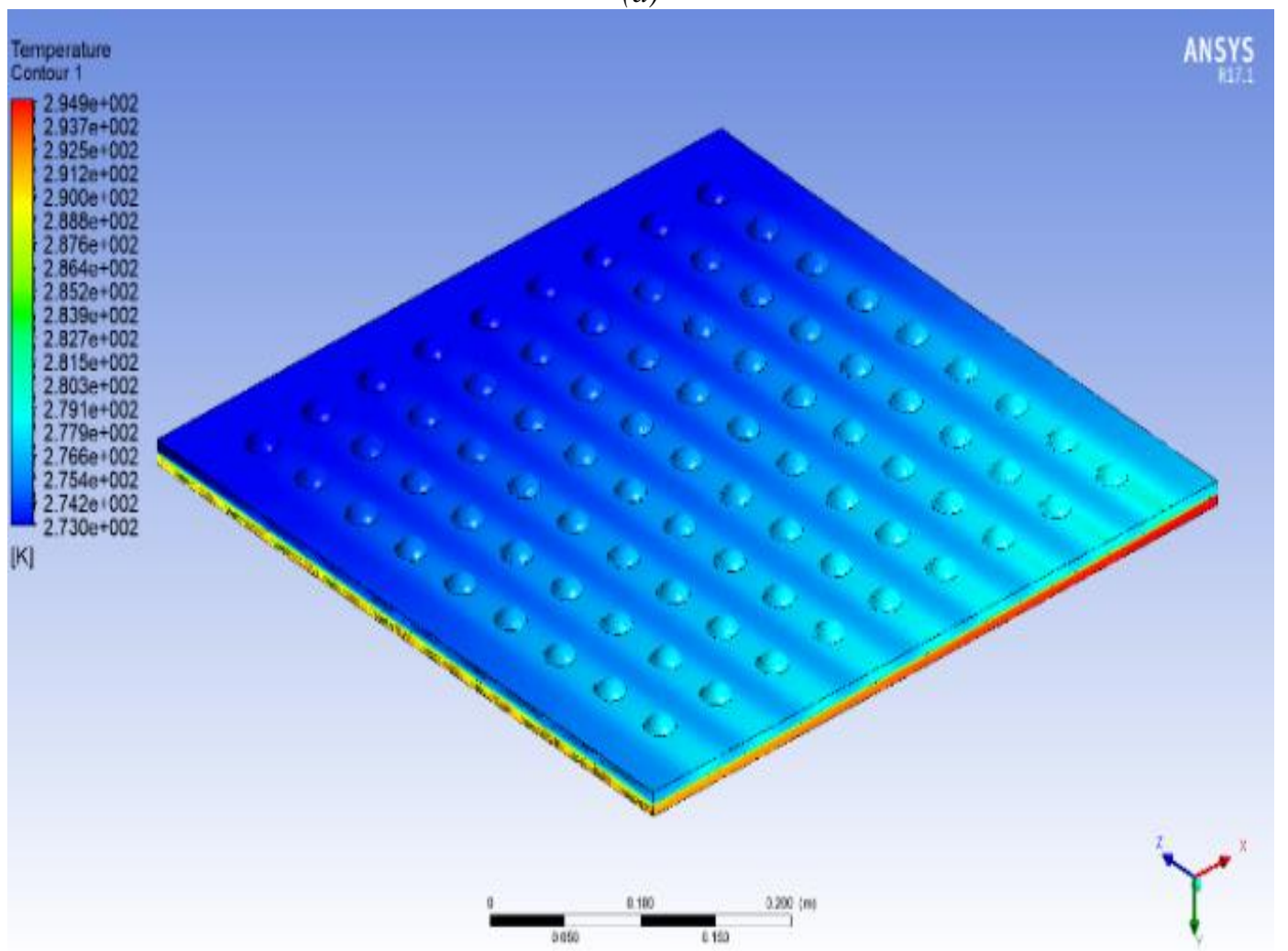

(b)

Figure 12. Temperature contour of cross-flow model: a) Hot fluid side, b) Cold fluid side

As a result of these analyses, heat transfer was increased with the addition of dimples to the plate surface, both increasing the heat transfer area and causing more turbulence in the flow. However, the addition of dimples has also caused the pressure drop to increase. Although pressure drop is not one of the most important parameters for heat exchangers, it has an important place in heat recovery ventilation systems. The reason for this is that the fan needs more power in systems that increase the heat transfer and the 
pressure drop is high. More fan power is required to draw air due to pressure drop. As a result of this, certain decreases occur in energy recovery while providing heat recovery. This is why ideal heat recovery ventilation systems both improve heat transfer and reduce pressure drop to a minimum.

These two analyzes have shown how surface geometries that increase the heat transfer area, such as dimples, increase the temperature of the cold air and affects heat transfer. The temperature contours of the hot fluid side and cold fluid side of a cross-flow model are given in Fig. 12 as an example. It also caused a pressure drop. However, with certain surface improvements, both heat transfer can be increased, while pressure drop can be minimized. After the addition of dimples, heat transfer and pressure drop were observed by changing the dimple diameters. In addition to $22 \mathrm{~mm}$ dimple, $26 \mathrm{~mm}$ and $30 \mathrm{~mm}$ dimple models were analyzed. The same mesh structure in the dimple analysis were used in the influence of dimple diameter (see Table 8).

Table 8. Dimple diameter analysis results.

\begin{tabular}{cccccc}
\hline \multirow{2}{*}{ Model } & \multirow{2}{*}{ Diameter $(\mathrm{mm})$} & \multicolumn{2}{c}{ Outlet Temperature $\left({ }^{\circ} \mathrm{C}\right)$} & \multirow{2}{*}{ Pressure Drop $(\mathrm{Pa})$} & \multirow{2}{*}{ Heat Transfer $(\mathrm{W})$} \\
\cline { 3 - 4 } & & Cold Side & Hot Side & \multirow{2}{*}{ Precc } \\
\hline dd-22 & 22 & 5.19 & 16.80 & 28.78 & 207.80 \\
dd-26 & 26 & 5.26 & 16.44 & 63.19 & 210.48 \\
dd-30 & 30 & 5.60 & 16.39 & 69.29 & 214.08 \\
\hline
\end{tabular}

There was a temperature increase of $5.5^{\circ} \mathrm{C}$ on the cold side. At the same time, there was the same decrease in the hot side. The $8 \mathrm{~mm}$ increase in diameter caused a $0.4^{\circ} \mathrm{C}$ increase in cold air temperature. Also, as the diameter increased, an increase in heat transfer was also observed. This was because the increase in diameter increases the plate area. An object with a wider area has more surface particles working to conduct heat. As such, the rate of heat transfer is directly proportional to the surface area through which the heat is being determined. The best heat transfer was in dd-30 model due to the increase of the plate area of the dimple area, thus the increase of the heat transfer area.

At the same time, an increase in pressure drop was observed with increasing diameter. The pressure drop occurs due to the frictional forces of a fluid that effects the fluid flow. Increasing the friction area of the dimple diameter caused an increase in resistance to flow. For this reason, the pressure drop increased as the dimple diameter increased. The pressure drop increased by $140 \%$ while heat transfer increased by $3 \%$. Although it seems like a high percentage, its effect cannot be seen correctly without calculating the fan power.

\subsubsection{Influence of waves on counter-flow}

First counter flow heat exchange analyzes were performed on flat plate and wavy plate to observe the effect of wave elements on heat transfer and pressure drop. The values found in the analysis are shown in Table 9.

Table 9. Flat and wavy plate comparison.

\begin{tabular}{ccccc}
\hline \multirow{2}{*}{ Model } & \multicolumn{2}{c}{ Outlet Temperature $\left({ }^{\circ} \mathrm{C}\right)$} & \multirow{2}{*}{ Pressure Drop $(\mathrm{Pa})$} & \multirow{2}{*}{ Heat Transfer $(\mathrm{W})$} \\
\cline { 2 - 4 } & Cold Side & Hot Side & & \\
\hline Flat & 13.21 & 8.78 & 77.87 & 108.82 \\
Wavy & 13.51 & 8.50 & 94.00 & 122.94 \\
\hline
\end{tabular}




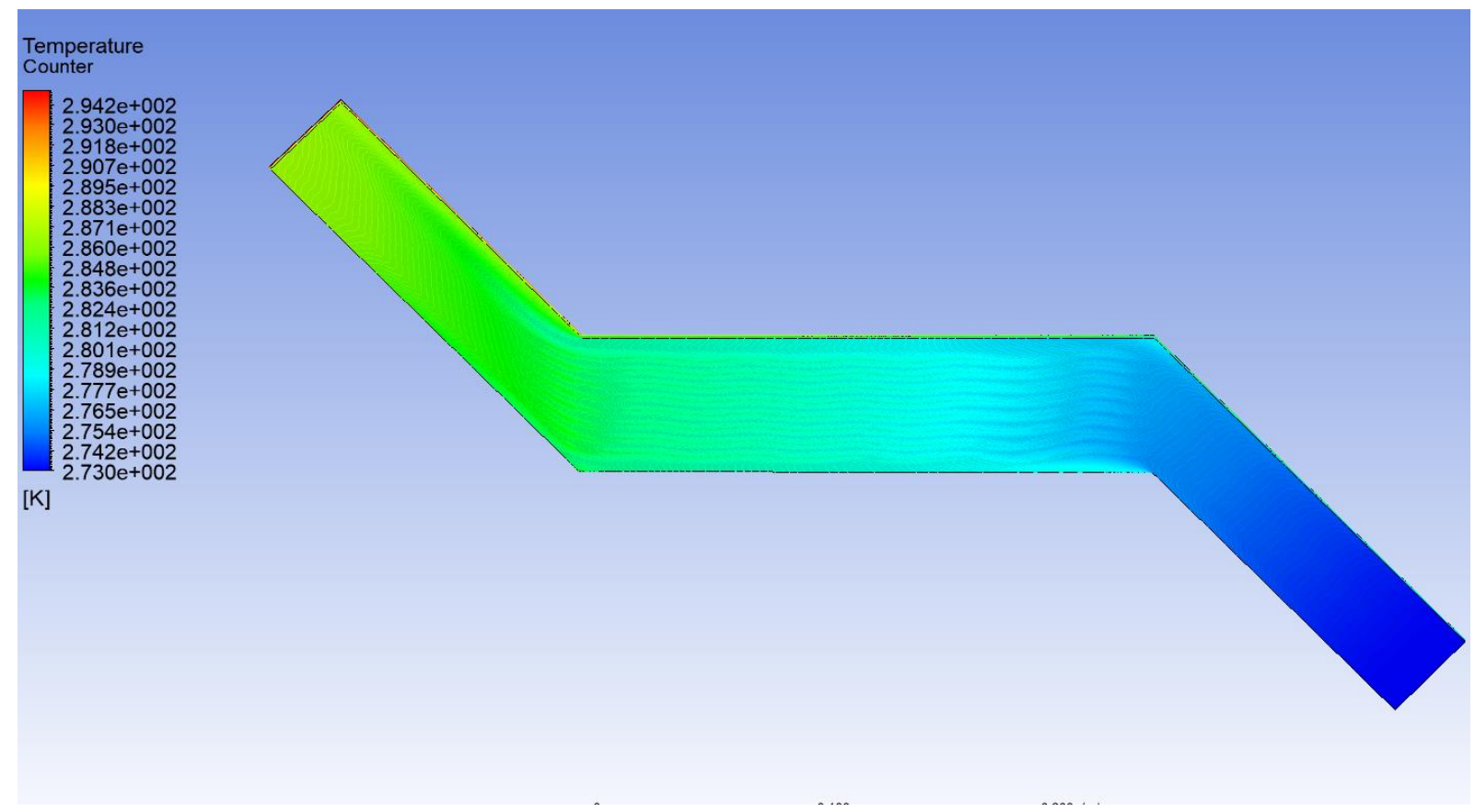

Figure 13. Temperature contours of wavy plate model.

These values are recalculated for the whole system by using the analysis area results. As seen in the table, the wave addition caused an increase in all parameters. The cold side temperature increase was $0.3^{\circ} \mathrm{C}$. Although the waves did not have a great effect because they are only placed in the middle part, they provided $20 \%$ increase in pressure drop and $12 \%$ increase in heat transfer. The reason for this can be interpreted as the fact that even though the waves didn't increase the area much, they caused disturbance for the flow in the middle, thus caused more turbulence. The pressure drop has increased as the waves constantly disrupt the flow and therefore the fluid crashes against the walls. As seen in the Fig. 13, the temperature increase was higher in the part where there are waves.

\subsubsection{Effects of protrusions angle on counter-flow}

These analyzes were performed to observe the effect of the angles of the protrusions added to the channel inlets and outlets on heat transfer and pressure drop. By keeping the protrusion numbers and locations constant, a full angle effect was observed. Fixed parameters given in counter analysis were used in the solution section. The results of the analysis for 6 angles are given in Table 10 .

Table 10. Effects of angles of cylindrical protrusions results.

\begin{tabular}{cccccc}
\hline \multirow{2}{*}{ Model } & \multirow{2}{*}{ Angle } & \multicolumn{2}{c}{ Outlet Temperature $\left({ }^{\circ} \mathrm{C}\right)$} & \multirow{2}{*}{ Pressure Drop (Pa) } & \multirow{2}{*}{ Heat Transfer (W) } \\
\cline { 3 - 5 } & Cold Side & Hot Side & T & \\
\hline Ap-0 & $0^{\circ}$ & 14.12 & 7.87 & 145.72 & 127.93 \\
Ap-15 & $15^{\circ}$ & 14.01 & 7.99 & 136.57 & 126.93 \\
Ap-30 & $30^{\circ}$ & 13.99 & 8.01 & 129.38 & 126.75 \\
Ap-45 & $45^{\circ}$ & 13.94 & 8.06 & 119.70 & 126.30 \\
Ap-68 & $68^{\circ}$ & 13.78 & 8.22 & 104.85 & 124.86 \\
Ap-90 & $90^{\circ}$ & 13.62 & 8.38 & 98.92 & 123.40 \\
\hline
\end{tabular}




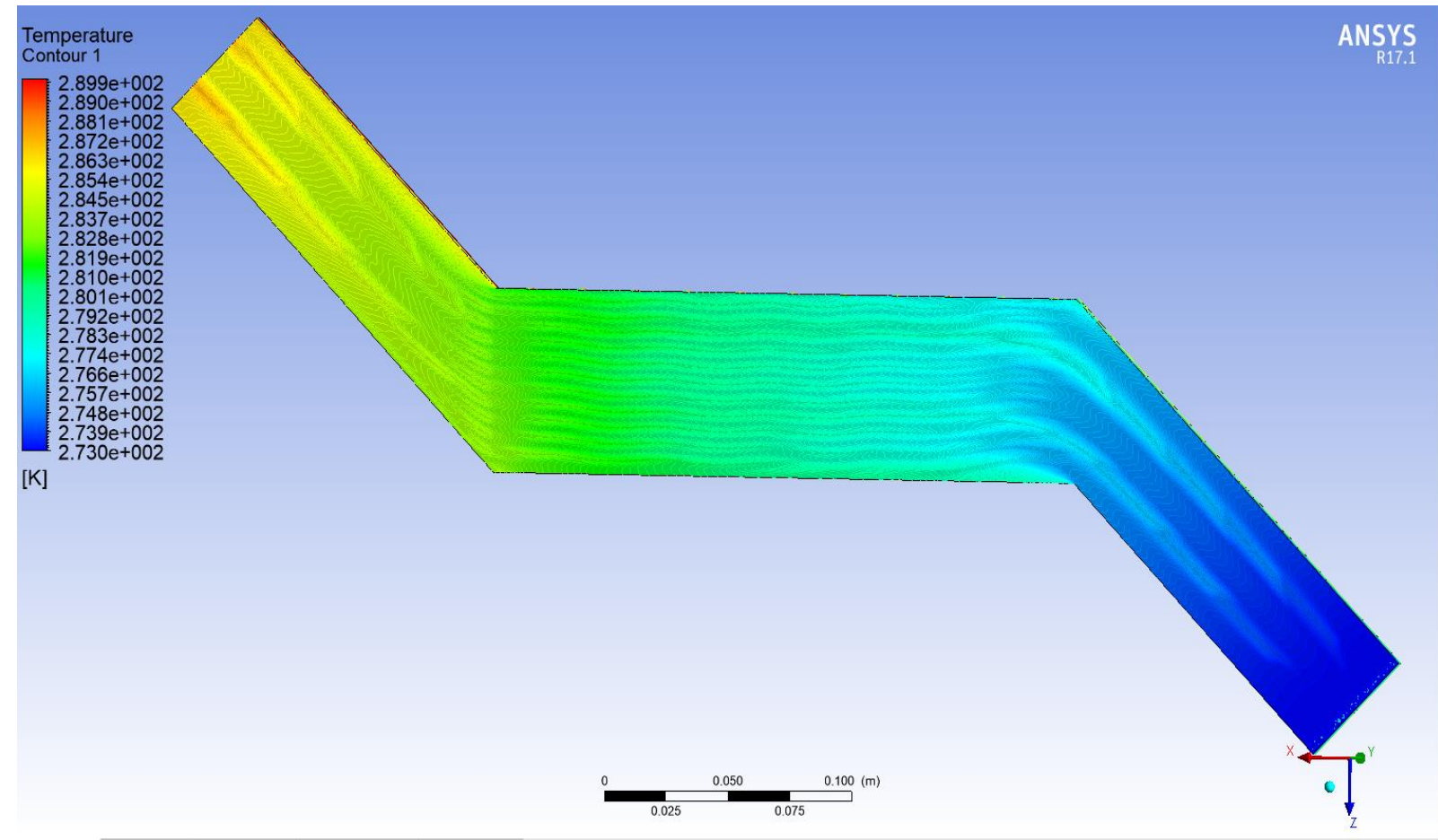

Figure 14. Temperature contours of wavy and protruded plate

As the angle of the cylindrical protrusions changes from $90^{\circ}$ to $0^{\circ}$, there was a $4 \%$ increase in heat transfer, while this increase was $45 \%$ in the pressure drop. At the same time, a temperature increases of $0.5^{\circ} \mathrm{C}$ was observed. The reason for these increases was that the mass, which disrupt the flow area increases as the degree goes from $90^{\circ}$ to $0^{\circ}$. Which means that the cross-sectional area when the fluid hits at $0^{\circ}$ is more and this area decreases as the angle increases. Turbulence increases as the crosssectional area hit by the fluid increases, as a result of which an increase in both heat transfer and pressure drop was observed. As seen in the Fig. 14, when the cold flow is viewed, it can be seen that the temperature increase was higher in the parts where the cylinder protrusions are located.

\subsubsection{Influence of channel height in counter-flow}

These analyzes were performed to observe the effect of channel height on heat transfer and pressure drop. Analyzes were made at $4 \mathrm{~mm}$ and $3 \mathrm{~mm}$ channel heights for 3 different angles. Only the duct height was changed, keeping the plate designs the same. In the solution part, fixed values given in the counter analysis are used. Analysis results are given in the Table 11.

Table 11. Effect of air channel height results.

\begin{tabular}{llccccc}
\hline \multirow{2}{*}{ Model } & \multirow{2}{*}{ Angle } & \multirow{2}{*}{ Channel Height $(\mathrm{mm})$} & \multicolumn{2}{c}{ Outlet Temperature $\left({ }^{\circ} \mathrm{C}\right)$} & \multirow{2}{*}{ Pressure Drop $(\mathrm{Pa})$} & \multirow{2}{*}{ Heat Transfer $(\mathrm{W})$} \\
\cline { 4 - 6 } Ap-0 & \multirow{2}{*}{$0^{\circ}$} & 4 & Cold Side & Hot Side & & \\
& & 3 & 14.12 & 7.87 & 145.72 & 127.93 \\
\multirow{2}{*}{ Ap-45 } & \multirow{2}{*}{$45^{\circ}$} & 4 & 13.92 & 5.07 & 329.78 & 104.52 \\
\hline \multirow{2}{*}{ Ap-90 } & \multirow{2}{*}{$90^{\circ}$} & 3 & 16.91 & 5.06 & 119.70 & 126.30 \\
& & 3 & 13.62 & 8.38 & 254.40 & 104.46 \\
\hline
\end{tabular}

Unlike other analysis, this time pressure drop and heat transfer are inversely proportional. While the heat transfer decreased by about $18 \%$, the pressure drop increased by an average of $120 \%$. First of all, it can be said that the reason for this change in heat transfer occurs with the decrease in the mass flow rate caused by the channel reduction. As for the pressure drop, as the channel narrows, the area through which the flow passes over the protrusions also narrows, causing pressure drop to increase. Also, there was an average increase of $3^{\circ} \mathrm{C}$ in temperature change. The cause of the change in temperature can be 
attributed to the changing mass flow rate as the channel narrows. The decrease in the mass flow rate as the channel became smaller caused the temperature change to increase.

\subsection{Thermal Performance Analysis}

Thermal performance analyzes were carried out to evaluate the performance of heat exchanger plate models in a whole heat exchanger and ventilation system. In these analyzes, in addition to the temperature, heat transfer and pressure drop in design analyzes, thermal efficiencies were also examined. At the same time, net power values are calculated for better understanding. Since the cross-flow and counter-flow plate sizes and designs are different, the number of plates was determined by taking the area covered by the heat exchanger as constant.

For thermal performance evaluation, the effect of velocity on heat transfer and pressure drop was observed by performing a velocity analysis in cross-flow design. Analyzes were made using 3, 5 and 8 $\mathrm{m} / \mathrm{s}$ values. All parameters except velocity were kept constant. The results are given in Table 12 .

As can be seen in Table 12, heat transfer and pressure drop both showed a noticeable increase as the velocity increased. The pressure drop increased by an average of five times with the increase in velocity in all designs, while the heat transfer doubled. Velocity is a function of the flow rate of the fluid and the volume of the path that the fluid follows. It is also one of the parameters that affect the flow form. The increase in velocity causes the number of Reynolds to increase, which causes the flow to be turbulent after a certain point. The turbulence constantly pushes the air into the walls, thereby increasing the volume of fluid that comes into contact with the walls of the heat exchanger, which leads to increase in heat transfer. As a result, higher the velocity higher the turbulence, and higher the turbulence, more efficient the heat transfer. Another reason for this increase is that the increase in velocity causes an increase in mass flow rate. Mass flow rate also has a direct proportional effect on heat transfer. As for pressure drop, friction is known to cause pressure drop. With the turbulence created by the velocity and flow, the friction created on the wall by the fluid caused the pressure drop to increase.

Table 12. Velocity analysis of cross-flow heat exchanger.

\begin{tabular}{cccccc}
\hline \multirow{2}{*}{ Diameter $(\mathrm{mm})$} & \multirow{2}{*}{ Velocity $(\mathrm{m} / \mathrm{s})$} & \multicolumn{2}{c}{ Outlet Temperature $\left({ }^{\circ} \mathrm{C}\right)$} & \multirow{2}{*}{ Pressure Drop $(\mathrm{Pa})$} & Heat Transfer $(\mathrm{W})$ \\
\cline { 3 - 4 } & & Cold Side & Hot Side & & \\
\hline \multirow{2}{*}{22} & 3 & 6.05 & 15.95 & 23.72 & 144.85 \\
& 5 & 5.19 & 16.80 & 28.78 & 207.80 \\
& 8 & 4.50 & 17.49 & 132.84 & 286.92 \\
\hline \multirow{2}{*}{26} & 3 & 6.21 & 15.79 & 26.612 & 148.78 \\
& 5 & 5.26 & 16.44 & 63.187 & 210.48 \\
& 8 & 4.60 & 17.40 & 147.52 & 287.60 \\
\hline \multirow{2}{*}{30} & 3 & 6.60 & 15.65 & 27.93 & 158.02 \\
& 5 & 5.60 & 16.39 & 69.29 & 214.08 \\
& 8 & 4.90 & 17.10 & 163.37 & 313.51 \\
\hline
\end{tabular}

Velocity and heat transfer are inversely proportional. Since the fan power is also taken into account in addition to heat transfer in thermal performance analyzes and the fan is directly affected by the pressure drop, it has been decided that the $5 \mathrm{~m} / \mathrm{s}$ velocity was the most appropriate considering the results.

\subsubsection{Cross-flow heat exchanger}

Using the analysis values for a single channel ( $5 \mathrm{~m} / \mathrm{s}$ velocity), calculations were made for 90 plates with $6.5 \mathrm{~mm}$ channel height. The $\mathrm{kWh}$ values are calculated by assuming that the system operates 3 months and 8 hours daily in winter and given in Table 13. 
Table 13. Cross-flow thermal performance results.

\begin{tabular}{cccccc}
\hline Model & $\begin{array}{c}\text { Heat Transfer } \\
(\mathrm{kW})\end{array}$ & $\begin{array}{c}\text { Fan Power } \\
(\mathrm{kW})\end{array}$ & $\begin{array}{c}\text { Net Power } \\
(\mathrm{kw})\end{array}$ & $\begin{array}{c}\text { Net Power } \\
(\mathrm{kWh})\end{array}$ & $\begin{array}{c}\text { Thermal Efficiency } \\
(\%)\end{array}$ \\
\hline Flat & 7.2 & 0.04 & 7.16 & $6,873.6$ & $18.09 \%$ \\
dd-22 & 18.70 & 0.04 & 18.66 & $17,911.17$ & $23.59 \%$ \\
dd-26 & 18.94 & 0.10 & 18.85 & $18,092.43$ & $23.90 \%$ \\
dd-30 & 19.27 & 0.10 & 19.17 & $18,398.53$ & $25.45 \%$ \\
\hline
\end{tabular}

Looking at the values, it can be seen that the dimple additions increase the heat transfer by about 3 times. Pressure drop, on the other hand, does not change much in the first dimple attachment, but increases with increasing diameter. As for the thermal efficiency, an increase of approximately $7.5 \%$ was observed with additions. When all models are compared, the $30 \mathrm{~mm}$ dimple model can be said to be the best in every aspect.

\subsubsection{Counter-flow heat exchanger}

Thermal performance analyzes were made by using the analysis values for a single channel $(5 \mathrm{~m} / \mathrm{s}$ velocity) and calculations were made for different number of plates. In order to compare the channels in the system, the height of the system was taken equal. Therefore, $3 \mathrm{~mm}$ channel height values were found using 195 plates and $4 \mathrm{~mm}$ channel height values were found using 145 plates. Thermal performance analysis was made for all counter-flow designs. Thus, it can be seen more easily how small design changes affect the whole system, such as angle and channel height. Unlike other analyzes, the effect of pressure drop was seen more clearly in these analyzes. The $\mathrm{kWh}$ values are calculated by assuming that the system operates 3 months and 8 hours daily in winter. The results are shown in Table 14.

Table 14. Counter-flow thermal performance results

\begin{tabular}{ccccccc}
\hline Model & $\begin{array}{c}\text { Channel Height } \\
(\mathrm{mm})\end{array}$ & $\begin{array}{c}\text { Heat Transfer } \\
(\mathrm{kW})\end{array}$ & $\begin{array}{c}\text { Fan Power } \\
(\mathrm{kW})\end{array}$ & $\begin{array}{c}\text { Net P } \\
(\mathrm{kW})\end{array}$ & $\begin{array}{c}\text { Net Energy } \\
(\mathrm{kWh})\end{array}$ & $\begin{array}{c}\text { Thermal } \\
\text { Efficiency }(\%)\end{array}$ \\
\hline Flat Plate & & 15.78 & 0.14 & 15.63 & $15,009.10$ & $60.00 \%$ \\
Waved Plate & & 17.83 & 0.16 & 17.67 & $16,960.90$ & $61.40 \%$ \\
Ap-0 & & 18.55 & 0.30 & 18.25 & $17,521.14$ & $64.20 \%$ \\
Ap-15 & 4 & 18.41 & 0.28 & 18.13 & $17,400.26$ & $63.70 \%$ \\
Ap-30 & & 18.38 & 0.26 & 18.11 & $17,389.26$ & $63.60 \%$ \\
Ap-45 & & 18.31 & 0.25 & 18.07 & $17,345.21$ & $63.40 \%$ \\
Ap-68 & & 18.11 & 0.25 & 17.86 & $17,145.73$ & $62.60 \%$ \\
Ap-90 & & 17.89 & 0.20 & 17.69 & $16,982.22$ & $61.90 \%$ \\
\hline Ap-0 & & 20.38 & 0.62 & 19.76 & $18,972.02$ & $76.90 \%$ \\
Ap-45 & 3 & 20.37 & 0.48 & 19.89 & $19,097.89$ & $76.90 \%$ \\
Ap-90 & & 20.00 & 0.37 & 19.63 & $18,841.29$ & $75.50 \%$ \\
\hline
\end{tabular}

As seen in the table, the values increase with add-ons from the flat platform. System values are mostly not different from channel analysis results. However, $0^{\circ}$ and $45^{\circ}$ angled plate values used in channel analysis vary. Considering the results of the $4 \mathrm{~mm}$ channel height, the heat transfer values of $0^{\circ}$ were higher than $45^{\circ}$, while the difference in the $3 \mathrm{~mm}$ channel height was almost zero. With this decrease, pressure drop values made a difference. With the increase of fan power due to the pressure drop, the net power decreased for the $0^{\circ}$ angle plate. While the best design in channel analysis was $0^{\circ}$ angle in both channel heights, the best design was $45^{\circ}$ angle $3 \mathrm{~mm}$ design among the counter-flow plate designs.

\subsection{Economic Analysis}

Analyzes were made using the simple payback, discounted payback and net present value methods described in the economic analysis method section. The values were taken from the thermal performance analysis and the analyzes were made considering the life of the heat exchanger as 10 years. The natural gas fee per $\mathrm{m}^{3}$ was assumed to be 1.74 (も) (\$0.21) [20]. For the unit conversion, $1 \mathrm{~m}^{3}$ natural gas was 
taken equal to $10.8 \mathrm{kWh}$. As for methods, the inflation rate was accepted as $12.75 \%$. The results were analyzed as cross-flow and counter-flow.

\subsubsection{Cross-flow heat exchanger}

Economic calculation was made on net power, at a velocity of $5 \mathrm{~m} / \mathrm{s}$ based on 90 plates of all three designs. Yearly savings were calculated over these values. The results of the calculations are shown in Table 15.

Table 15. Cross-flow HEX Yearly savings.

\begin{tabular}{ccccccc}
\hline Model & $\begin{array}{c}\text { Heat Transfer } \\
(\mathrm{kW})\end{array}$ & $\begin{array}{c}\text { Fan Power } \\
(\mathrm{kW})\end{array}$ & $\begin{array}{c}\text { Net Energy } \\
(\mathrm{kWh})\end{array}$ & $\begin{array}{c}\text { Natural Gas } \\
\left(\mathrm{m}^{3}\right)\end{array}$ & Cost $\left(\right.$ per $\left.\mathrm{m}^{3}\right)$ & Yearly Saving \\
\hline $\mathrm{dd}-22$ & 18.7 & 0.04 & $17,911.17$ & $1,658.44$ & $\$ 0.21$ & $\$ 348.27$ \\
dd-26 & 18.94 & 0.1 & $18,092.43$ & $1,675.22$ & $\$ 0.21$ & $\$ 351.80$ \\
dd-30 & 19.27 & 0.1 & $18,398.53$ & $1,703.57$ & $\$ 0.21$ & $\$ 357.75$ \\
\hline
\end{tabular}

After finding the yearly savings, and the selected methods are applied. The average wages for 90 plates purchased from the companies are $\$ 320.93$ for HEX and \$770.23 for AHU. First, Simple Payback period calculation was made for both HEX and AHU. Then, Discounted Payback method and NPV methods were used to make a more accurate effect on decision making. Since the life of heat exchangers is 10 years, economic calculations are made for 10 years. The results of these calculations are shown in Table 16.

Table 16. Cross-flow economic analyzes results for HEX and AHU.

\begin{tabular}{ccccc}
\hline & Model & $\begin{array}{c}\text { Simple Payback } \\
\text { Period (years) }\end{array}$ & $\begin{array}{c}\text { Discounted Payback } \\
\text { Period (years) }\end{array}$ & Net Present Value \\
\hline \multirow{3}{*}{ HEX } & dd-22 & 0.92 & 1.04 & $\$ 1,587.92$ \\
& dd-26 & 0.92 & 1.03 & $\$ 1,607.23$ \\
& dd-30 & 0.89 & 1.01 & $\$ 1,639.86$ \\
\hline \multirow{2}{*}{ AHU } & dd-22 & 2.21 & 1.79 & $\$ 1,138.62$ \\
& dd-26 & 2.18 & 1.78 & $\$ 1,157.93$ \\
& dd-30 & 2.15 & 1.76 & $\$ 1,190.56$ \\
\hline
\end{tabular}

Considering the results of all economical methods, it is clear that the Dimple 30mm design is faster and higher turnaround compared to both AHU and HEX results. NPV and Discount Payback methods are used for these results. Among the designs made with these results, it was observed that the system having the optimum values in terms of both system and economy is the design of $30 \mathrm{~mm}$ dimple, dd- 30 .

\subsubsection{Counter-flow heat exchanger}

Economic calculations are made for designs used in effect of channel height analysis. In order to see the economic effects, these designs were chosen due to both channel and design differences. Yearly savings were calculated over these values. The results of the calculations are shown in Table 17.

Table 17. Counter-flow HEX yearly savings.

\begin{tabular}{ccccccc}
\hline Model & $\begin{array}{c}\text { Heat Transfer } \\
(\mathrm{kW})\end{array}$ & $\begin{array}{c}\text { Fan Power } \\
(\mathrm{kW})\end{array}$ & $\begin{array}{c}\text { Net Energy } \\
(\mathrm{kWh})\end{array}$ & $\begin{array}{c}\text { Natural Gas } \\
\left(\mathrm{m}^{3}\right)\end{array}$ & $\begin{array}{c}\text { Cost } \\
\left(\text { per m}^{3}\right)\end{array}$ & Yearly Saving \\
\hline Ap-0 4 mm & 18.55 & 0.3 & $17,521.14$ & $1,622.33$ & $\$ 0.21$ & $\$ 340.69$ \\
Ap-45 4 mm & 18.31 & 0.25 & $17,345.21$ & $1,606.04$ & $\$ 0.21$ & $\$ 337.27$ \\
Ap-90 4 mm & 17.89 & 0.2 & $16,982.22$ & $1,572.43$ & $\$ 0.21$ & $\$ 330.21$ \\
Ap-0 3 mm & 20.38 & 0.62 & $18,972.02$ & $1,756.67$ & $\$ 0.21$ & $\$ 368.90$ \\
Ap-45 3 mm & 20.37 & 0.48 & $19,097.89$ & $1,768.32$ & $\$ 0.21$ & $\$ 371.35$ \\
Ap-90 3 mm & 20 & 0.37 & $18,841.29$ & $1,744.56$ & $\$ 0.21$ & $\$ 366.36$ \\
\hline
\end{tabular}


After finding the yearly savings, selected methods were applied. Since different plate numbers were used in the counter flow heat exchanger, prices were taken per plate. Average price received from companies were \$1.24 for HEX and \$3.24 for AHU. These prices are different for cross and counter flow heat exchangers. These price differences are caused by the thickness, design, prints and areas of the plates. First, Simple Payback time calculation was made for both HEX and AHU. Then, Discounted Payback method and NPV methods were used to have a more accurate result. Since the heat exchangers have a lifetime of 10 years, economic calculations are made for 10 years. The results of the calculated economic analysis are given Table 18.

Table 18. Counter-flow economic analysis results.

\begin{tabular}{ccccc}
\hline Model & $\begin{array}{c}\text { Simple Payback } \\
\text { Period (years) }\end{array}$ & $\begin{array}{c}\text { Discounted Payback } \\
\text { Period (years) }\end{array}$ & Net Present Value \\
\hline \multirow{6}{*}{ HEX } & Ap-0 4mm & 0.52 & 0.60 & $\$ 1,687.48$ \\
& Ap-45 4mm & 0.53 & 0.60 & $\$ 1,668.73$ \\
Ap-90 4mm & 0.54 & 0.61 & $\$ 1,630.05$ \\
& Ap-0 3mm & 0.65 & 0.74 & $\$ 1,780.10$ \\
& Ap-45 3mm & 0.65 & 0.73 & $\$ 1,793.52$ \\
Ap-90 3mm & 0.66 & 0.74 & $\$ 1,766.17$ \\
\hline \multicolumn{6}{c}{ Ap-0 4mm } & 1.37 & 1.29 & $\$ 1,397.48$ \\
& Ap-45 4mm & 1.39 & 1.30 & $\$ 1,378.73$ \\
AHU & Ap-90 4mm & 1.42 & 1.32 & $\$ 1,340.05$ \\
& Ap-0 3mm & 1.71 & 1.49 & $\$ 1,390.10$ \\
& Ap-45 3mm & 1.70 & 1.49 & $\$ 1,403.52$ \\
Ap-90 3mm & 1.72 & 1.50 & $\$ 1,376.17$ \\
\hline
\end{tabular}

Considering the results, it is clear that according to both AHU and HEX results, Ap-0 model in $4 \mathrm{~mm}$ and Ap-45 model in $3 \mathrm{~mm}$ get faster and higher return. Overall, it was observed that the best design for both AHU and HEX is Ap-45 $3 \mathrm{~mm}$ design.

\subsection{Environmental Analysis}

Environmental analyzes are made by taking natural gas as the fluid of the system. It was assumed that the heat exchangers designed in this project will be used for the air handling unit. Therefore, since generally natural gas is used as fuel, calculations are made with natural gas emission value. The results were analyzed using thermal performance analysis values for cross-flow and counter-flow.

\subsubsection{Cross-flow heat exchanger}

Environmental effects are calculated for all three dimple diameter designs of cross-flow. These models are dd-22, dd-26 and dd-30 and the results are shown in Table 19.

Table 19. Cross-flow environmental analysis results.

\begin{tabular}{ccccc}
\hline Model & Net Power $(\mathrm{kW})$ & Net Energy $(\mathrm{kWh})$ & $\mathrm{kg} \mathrm{CO}_{2} / \mathrm{kWh}$ & $\mathrm{kg} \mathrm{CO}_{2} /$ time \\
\hline dd-22 & 18.66 & $17,911.17$ & 0.443 & $7,934.65$ \\
dd-26 & 18.85 & $18,092.43$ & 0.443 & $8,014.94$ \\
dd-30 & 19.17 & $18,398.53$ & 0.443 & $8,150.55$ \\
\hline
\end{tabular}

As can be seen, the systems using these designs reduce $\mathrm{CO}_{2}$ emission by at least 7,934 $\mathrm{kg}$ during their time of use. Among these designs, the best result was the dd-30 model with a reduced emission value of $8,150.55 \mathrm{~kg} \mathrm{CO}$. 


\subsubsection{Counter-flow heat exchanger}

Environmental effects are calculated for counter flow models with different angles and channel dimensions. These models are $3 \mathrm{~mm}$ and $4 \mathrm{~mm}$ channel designs for angles of $0^{\circ}, 45^{\circ}$ and $90^{\circ}$. The results are given in the Table 20.

Table 20. Counter-flow Environmental Analysis results.

\begin{tabular}{ccccc}
\hline Model & Net Power $(\mathrm{kW})$ & Net Energy $(\mathrm{kWh})$ & $\mathrm{kg} \mathrm{CO}_{2} / \mathrm{kWh}$ & $\mathrm{kg} \mathrm{CO}_{2} /$ time \\
\hline Ap-0 $4 \mathrm{~mm}$ & 18.20 & $17,473.96$ & 0.443 & $7,740.97$ \\
$\mathrm{Ap}-03 \mathrm{~mm}$ & 19.66 & $18,874.17$ & 0.443 & $8,361.26$ \\
Ap-45 $4 \mathrm{~mm}$ & 18.03 & $17,306.45$ & 0.443 & $7,666.76$ \\
Ap-45 3 mm & 19.82 & $19,022.48$ & 0.443 & $8,426.96$ \\
Ap-90 4 mm & 17.66 & $16,950.18$ & 0.443 & $7,508.93$ \\
Ap-90 3 mm & 19.57 & $18,782.79$ & 0.443 & $8,320.78$ \\
\hline
\end{tabular}

As a result of these calculations, minimum 7,500 $\mathrm{kg}$ and maximum 8,420 $\mathrm{kg} \mathrm{CO} 2$ emissions have been reduced with these designs. Among these designs, it can be said that the best design was Ap-45 3mm model in the environmental aspect.

\section{CONCLUSION}

In this study, design changes of cross-flow and counter-flow heat exchangers on heat transfer and pressure drop were investigated. By comparing the values found with each other, the accuracy of the solution method and values are ensured. The effect of design changes was observed by changing the dimensions and angles of different plate inserts, changing the channel height and velocity. As the results of the analyzes, it was observed that;

Additions to plate surface such as dimples, waves and protrusions, which increase the heat transfer area, increase the heat transfer and pressure drop. Depending on the size and layout angles of the additions, these parameters can vary.

As observed in velocity and channel analysis, changes that decrease mass flow rate decrease heat transfer while increasing temperature change.

Thermal efficiency increased from $18 \%$ to $60 \%$ when changing from cross flow to counter flow in flat plate design, while it increased from $25 \%$ to $77 \%$ in enhanced plate designs. This means an efficiency increase of $40-55 \%$ can be achieved with the same designs with flow change.

According to the analysis, the best design model in cross-flow was dd-30 model, which has $30 \mathrm{~mm}$ diameter, with 25\% thermal efficiency, while the best design in counter flow was Ap-45 3 mm design with 77\% thermal efficiency.

Compared to all design analysis, the best design was Ap-45 $3 \mathrm{~mm}$ counter-flow with $45^{\circ}$ angle and 3 $\mathrm{mm}$ channel height design. As a result, it can be said that this design is an optimum design in all aspects of systematic, environmental and economic. By using this system in the winter season for 8 hours daily for 3 months, an annual saving of $\$ 371.35$ is possible while at the same time a reduction of $8,427 \mathrm{~kg} \mathrm{CO}$ emission can be achieved.

\section{Acknowledgment}

The authors would like to express their gratitude to Mr. Deniz Zeybel and Trex Heat Exchangers Company for their support and help during the study. 


\section{REFERENCES}

[1] Fouih, YE, Stabat, P, Rivière, P, Hoanga, P, Archambault, V. Adequacy of air-to-air heat recovery ventilation system applied in low energy buildings. Energy and Building 2012; 54: 29-39.

[2] Kotcioglu, I, Caliskan, S, Zirzakıran, M. Heat Transfer in A Cross-Flow Heat Recovery Ventilator with Fin. Erciyes Üniv. Fen Bilimleri Enstitüsü Dergisi 2009; 25(1-2): 272 - 286

[3] Borjigin, S, Zhang, S, Ma, T, Zeng, M, Wang, Q. Performance enhancement of cabinet cooling system by utilizing cross-flow plate heat exchanger. Energy Conversion and Management 2020; 213: 112854.

[4] De Antonellis, S, Cignatta, L, Facchini, C, Liberati, P. Effect of heat exchanger plates geometry on performance of an indirect evaporative cooling system. Applied Thermal Engineering 2020: 115200.

[5] Xing, Y, Weigand, B. Experimental investigation of impingement heat transfer on a flat and dimpled plate with different crossflow schemes. International Journal of Heat and Mass Transfer 2010; 53: 3874-3886.

[6] Piper, M, Zibarta, A, Djakow, E, Springer, R, Homberg, W, Keniga, EY. Heat transfer enhancement in pillowplate heat exchangers with dimpled surfaces: A numerical study. Applied Thermal Engineering 2019; 153: 142-146.

[7] Kumar, P, Kumar, A, Chamoli S, Kumar, M. Experimental investigation of heat transfer enhancement and fluid flow characteristics in a protruded surface heat exchanger tube. Experimental Thermal and Fluid Science 2016; 71: 42-51.

[8] Vignesh, S, Moorthy, VS, Nallakumarasamy, G. Experimental and CFD Analysis of Concentric Dimple Tube Heat Exchanger. Int J Emerg Technol Eng Res (IJETER) 2017: 5(7): 18-26.

[9] Al-Zubaydi, A. Y. T., \& Hong, G. Experimental investigation of counter flow heat exchangers for energy recovery ventilation in cooling mode. International Journal of Refrigeration 2018; 93: 132-143.

[10] Dogan, S, Darici, S, Ozgoren M. Numerical comparison of thermal and hydraulic performances for heat exchangers having circular and elliptic cross-section. International Journal of Heat and Mass Transfer 2019; 145: 118731.

[11] Gholami, A, Mohammed, HA, Wahid, MA, Khiadani, M. Parametric design exploration of fin-and-oval tube compact heat exchangers performance with a new type of corrugated fin patterns. International Journal of Thermal Sciences 2019; 144: 173-190.

[12] Lee, J, Lee KS. Correlations and shape optimization in a channel with aligned dimples and protrusions. International Journal of Heat and Mass Transfer 2013; 64: 444-451.

[13] Ying, P, He, Y, Tang, H, \& Ren, Y. Numerical and Experimental Investigation of Flow and Heat Transfer in Heat Exchanger Channels with Different Dimples Geometries. Machines 2021; 9(4): 72.

[14] ASHRAE Handbook: Heating, Ventilating and Air-Conditioning Systems and Equipment. Atalanta GA, USA: American Society of Heating, Refrigerating and Air-Conditioning Engineers Inc., 2004.

[15] Teke, I, Agra, O, Atayılmaz, SO, Demir, H. Determining the best type of heat exchangers for heat recovery. Applied Thermal Engineering 2010; 30: 577-583.

[16] White, FM. Viscous Fluid Flow (3rd Edition). New York, USA: McGraw-Hill Mechanical Engineering, 1991.

[17] Internet Web-Site: https://eurovent.eu/?q=content/eurovent-1711-2015-guidelines-heat-recovery, Eurovent 17/11 - 2015 - Eurovent guidelines for Heat Recovery, August 2021.

[18] Sullivan, WG, Wicks, EM, Koelling, CP. Engineering Economy. Upper Saddle River, NJ, USA: Pearson Inc., 2014

[19] Miro, L, Mckenna, R, Jager, T, Cabeza, LF. Estimating the industrial waste heat recovery potential based on $\mathrm{CO}_{2}$ emissions in the European non-metalic mineral industry. Energy Efficiency 2018; 11: 427-443.

[20] Internet Web-Site: https://www.botas.gov.tr/Sayfa/2021-yili-mayis-ayi-dogal-gaz-toptan-satis-fiyattarifesi/531, Botaş Tarifeler [Botaş Tariffs], May 2021. 